\title{
The role of autophagy in asparaginase-induced immune suppression of macrophages
}

\author{
Ping Song ${ }^{1,2,5}$, Ziyu Wang ${ }^{1,3,5}$, Xuyao Zhang ${ }^{1,5}$, Jiajun Fan ${ }^{1}$, Yubin Li ${ }^{1}$, Qicheng Chen ${ }^{1}$, Shaofei Wang ${ }^{1}$, Peipei Liu ${ }^{1,4}$, Jingyun Luan ${ }^{1}$,

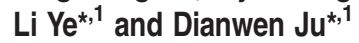

Erwinia asparaginase, a bacteria-derived enzyme drug, has been used in the treatment of various cancers, especially acute lymphoblastic leukemia (ALL). One of the most significant side effects associated with asparaginase administration is immune suppression, which limits its application in clinic. Macrophages are phagocytic immune cells and have a central role in inflammation and host defense. We reported here that asparaginase disturbed the function of macrophages including phagocytosis, proliferation, ROS and nitric oxide secretion, interleukin 6 (IL-6) and tumor necrosis factor $\alpha$ (TNF- $\alpha$ ) secretion, and major histocompatibility complex II (MHC-II) molecule expression, thus induced immune suppression in interferon- $\gamma$ and lipopolysaccharide-stimulated macrophages. We also observed that asparaginase inhibited autophagy in macrophages via activating Akt/mTOR and suppressing Erk1/2 signaling pathway as evidenced by less formation of autophagosomes, downregulation of autophagy-related protein LC3-II, and decreased number of autophagy-like vacuoles. Further study discovered that treatment with autophagy inhibitor 3-MA in place of asparaginase on activated macrophages could also downregulate phagocytosis, cytokine secretion, and MHC-II expression. Moreover, incubation with autophagy inducer trehalose restored the capacity of phagocytosis, IL- 6 and TNF- $\alpha$ secretion, and MHC-II expression in macrophages. These results prove the important role of autophagy in the function of macrophages, and activation of autophagy can overcome asparaginase-induced immune suppression in macrophages.

Cell Death and Disease (2017) 8, e2721; doi:10.1038/cddis.2017.144; published online 30 March 2017

Asparaginase, an enzyme drug derived from Erwinia, has been used for years in the treatment of acute lymphoblastic leukemia (ALL), myeloid leukemia, ovarian cancer, and T-cell lymphomas. ${ }^{1-4}$ Asparaginase depletes asparagine in the blood by hydrolyzing the amino acid asparagine and glutamine to aspartic acid and glutamic acid, thus the malignant tumor cells that depend on extracellular asparagine fail to survive. ${ }^{5}$ Asparagine deprivation mediated by bacteria-derived asparaginase similarly causes suppression of cellular processes and pathways that involved in immune response, and consequently initiates side effects, which limits its application in clinic. Previous study has found that administration of Escherichia coli asparaginase to mice was rapidly immunosuppressive. ${ }^{6}$ The extranodal natural killer/T-cell lymphoma (ENKTL) patients receiving asparaginase-based chemotherapy who have more adverse clinical features showed increased serum levels of interleukin (IL)-10. ${ }^{7}$ IL-10 is a pleiotropic cytokine involved in the stimulation and suppression of immune response, and mounting evidence suggests that IL-10 can inhibit various immune functions including macrophage activation, nitric oxide (NO) synthesis, pro-inflammatory cytokine secretion, and antigen presentation. $^{8-10}$ Asparaginase was reported to suppress
T-cell blastogenesis, cytokine production, and proliferation and to downmodulate expression of the T-cell receptor, then limits T-cell responses. ${ }^{11,12}$

Macrophages are an essential component of innate immunity and have a central role in inflammation and host defense. ${ }^{13,14}$ Macrophages are extremely plastic cells, and may undergo classical M1 activation (stimulated by interferon (IFN)- $\gamma$ and/or lipopolysaccharide; LPS) or alternative $\mathrm{M} 2$ activation (stimulated by IL-4/IL-13), which have distinct functional and phenotypical characteristics in response to various stimuli. ${ }^{15,16} \mathrm{M} 1$ macrophages exert pro-inflammatory and anti-tumor function characterized by high expression of pro-inflammatory cytokines, chemokines, reactive nitrogen intermediates, and reactive oxygen intermediates. By contrast, M2 macrophages have antiinflammatory and pro-wound healing activities. ${ }^{17-19}$ Despite impressive advances in the understanding of its immune suppression, whether asparaginase influences the function of macrophages is rarely addressed. Because of the important role of macrophages in the immune system, we employed IL-4 to activate macrophages to generate M2 macrophages, and found that asparaginase did not influence the IL-10 secretion in M2 macrophages. We speculated

\footnotetext{
${ }^{1}$ Department of Microbiological and Biochemical Pharmacy \& The Key Laboratory of Smart Drug Delivery, Ministry of Education, School of Pharmacy, Fudan University, 826 Zhangheng Road, Shanghai, 201203, P. R. China; ${ }^{2}$ Department of Pharmacy, Ruijin Hospital Luwan Branch, Shanghai, 200020, P.R. China; ${ }^{3}$ Department of Pharmacy, Huadong Hospital, Fudan University, Shanghai, 200040, P.R. China and ${ }^{4}$ Department of Analytical Science, Sunshine Guojian Pharmaceutical (Shanghai) Co. Ltd, Shanghai, 201203, P.R. China

${ }^{*}$ Corresponding author: Y Li or D Ju, Department of Microbiological and Biochemical Pharmacy \& The Key Laboratory of Smart Drug Delivery, Ministry of Education, School of Pharmacy, Fudan University, 826 Zhangheng Road, Shanghai 201203, P.R. China. Tel: +86 215198 0035; Fax: +86 215198 0036. E-mail: yelil @fudan.edu.cn or Tel: +86 215198 0037; Fax: +86 215198 0036; E-mail: dianwenju@fudan.edu.cn

${ }^{5}$ These authors contributed equally to this work.

Received 15.10.16; revised 25.2.17; accepted 28.2.17; Edited by GM Fimia
} 

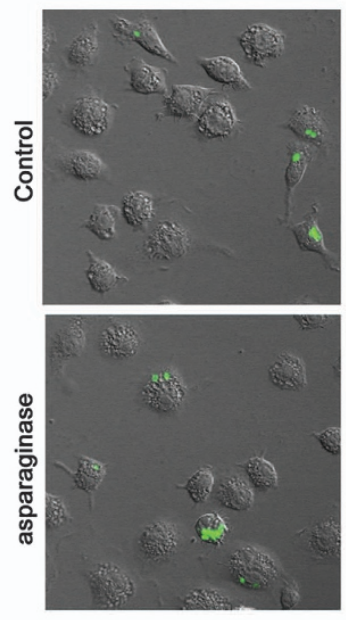

Ana-1

b

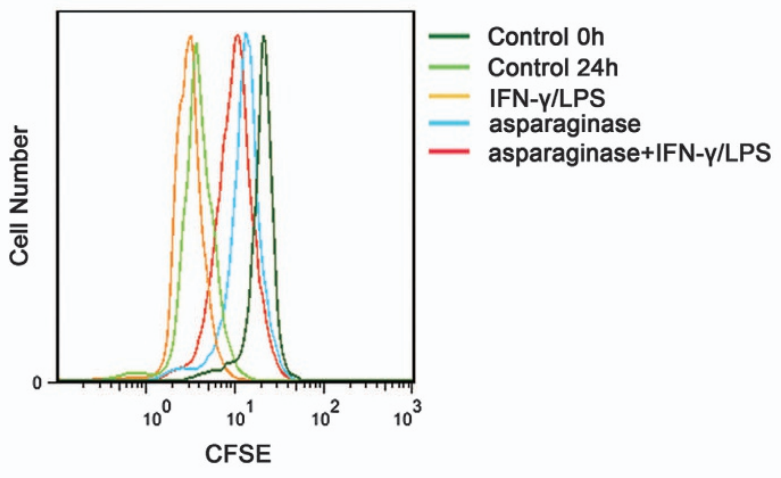

C

Ana-1

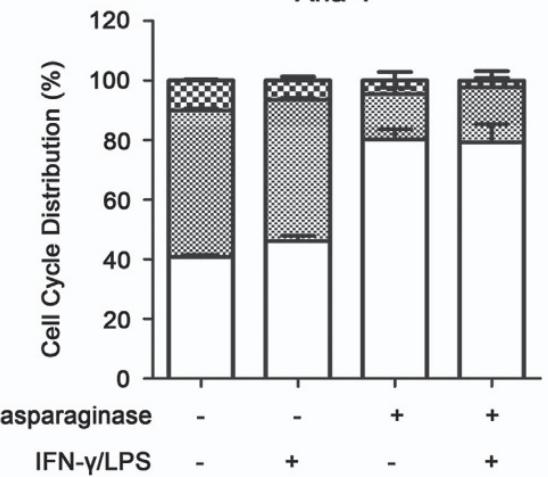

Ana-1
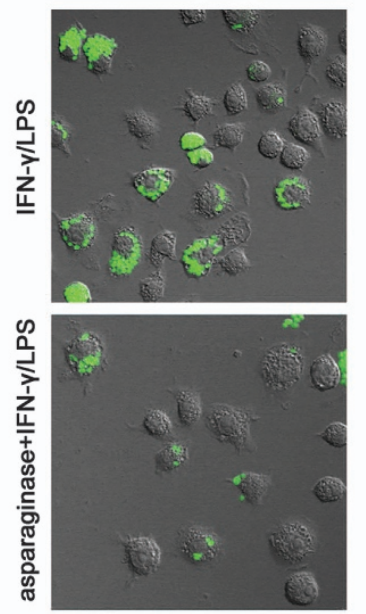

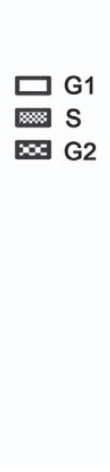

RAW264.7
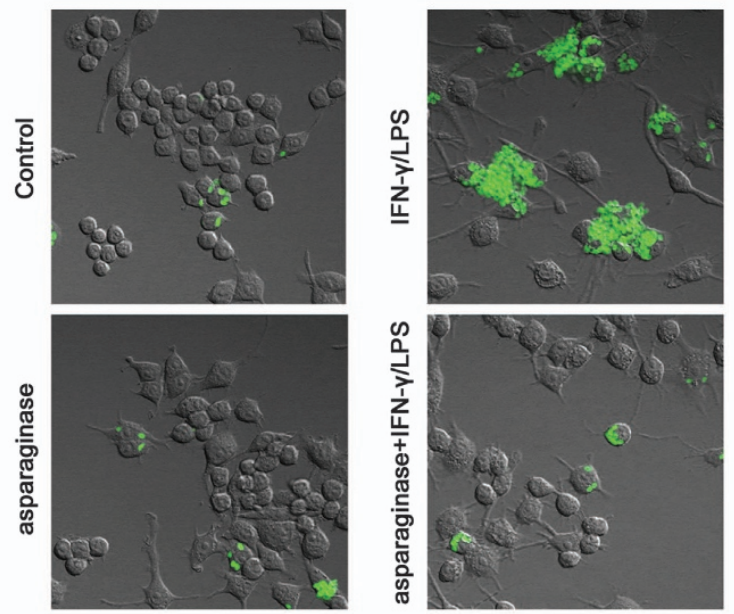

\section{RAW264.7}

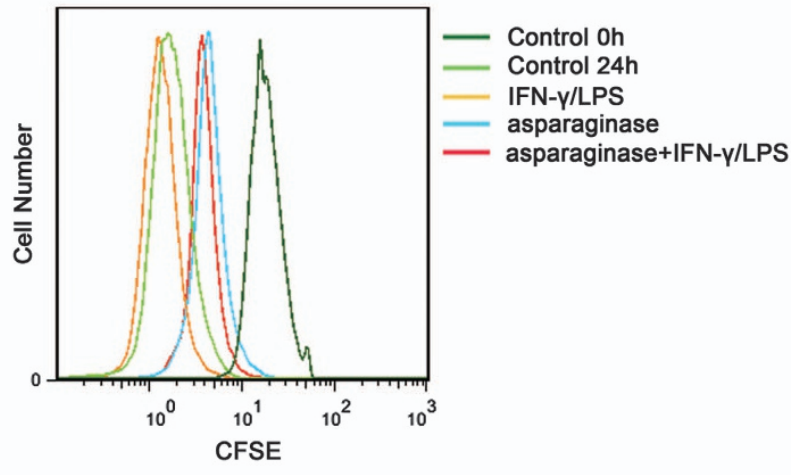

RAW264.7

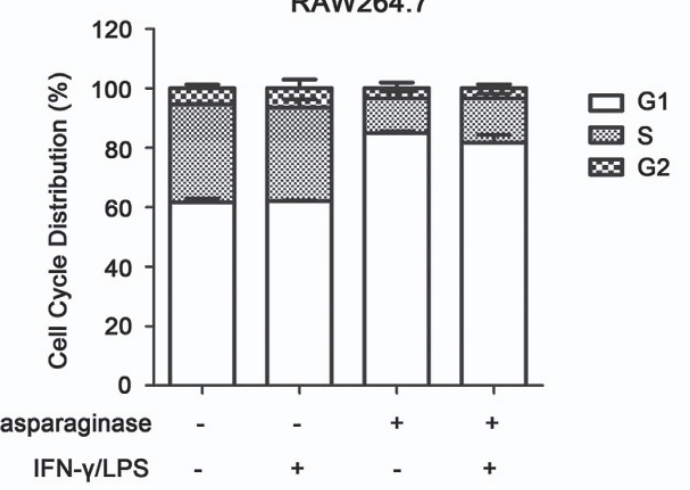

Figure 1 Phagocytosis and proliferation are inhibited by asparaginase in Ana-1 and RAW264.7 cells. (a) Ana-1 and RAW264.7 cells were treated with 300 IU/ml IFN- $\gamma$ and $200 \mathrm{ng} / \mathrm{ml}$ LPS, either alone or in combination with $0.1 \mathrm{lU} / \mathrm{ml}$ asparaginase for $24 \mathrm{~h}$. The cells were incubated with zymosan particles for another $2 \mathrm{~h}$, and analyzed by confocal fluorescent microscopy. (b) Ana-1 and RAW264.7 cells were labeled with CFSE, then incubated with $300 \mathrm{IU} / \mathrm{ml} \mathrm{IFN}-\gamma$ and $200 \mathrm{ng} / \mathrm{ml}$ LPS, either alone or in combination with $0.1 \mathrm{IU} / \mathrm{ml}$ asparaginase for $24 \mathrm{~h}$. The fluorescence intensity was analyzed by flow cytometry. Cells without treatment were used as control. (c) Ana-1 and RAW264.7 cells were treated with $300 \mathrm{IU} / \mathrm{ml} \mathrm{IFN}-\gamma$ and $200 \mathrm{ng} / \mathrm{ml}$ LPS, in the presence or absence of $0.1 \mathrm{IU} / \mathrm{ml}$ asparaginase for $24 \mathrm{~h}$, cell cycle distribution were analyzed by flow cytometry. The percentage of cells in different phases was presented in bar graphs

that asparaginase might mainly affect the function of M1 macrophages. ${ }^{20}$

To verify this hypothesis, we used IFN- $\gamma$ and LPS to stimulate macrophages to generate M1 macrophages. We found that asparaginase not only inhibited phagocytosis and proliferation of macrophage, but also downregulated auto- phagy in macrophages. Autophagy is a highly conserved cellular process in eukaryotes to maintain cellular homeostasis by supporting cell survival and regulating inflammation. ${ }^{21}$ Autophagy degrades unnecessary or dysfunctional intracellular components, such as abnormal proteins, old organelles, and pathogens, and has been widely 
studied in various immune cells, including $\mathrm{T}$ cell, B cell, macrophages, dendritic cells (DCs), and neutrophils. ${ }^{22-25}$ Recent studies suggest an important role of autophagy in regulating the immune response of macrophages. Macrophage autophagy regulates inflammation and insulin sensitivity. ${ }^{26,27}$ In obese mice, high-fat diet conditions (HFD)induced inflammatory conditions downregulate autophagy in macrophages, which promote the production of reactive oxygen species (ROS) and pro-inflammatory cytokines, further aggravating inflammation. ${ }^{28}$ Macrophages also participate in the process of atherosclerosis, and macrophage autophagy contributes to the inhibition of foam cell formation by reducing oxidized low density lipoprotein ingestion and inflammasome activation, and increasing efferocytosis and cholesterol efflux in macrophages. ${ }^{29,30}$ All of these results prompt us to explore the role of autophagy in asparaginaseinduced immune suppression of macrophages.

In this study, we demonstrate that Erwinia asparaginase induces obvious immune suppression as well as autophagy downregulation in IFN- $\gamma$ and LPS-stimulated macrophages. Further study elucidates that inhibition of autophagy restrains the function of macrophages including cytokine secretion, major histocompatibility complex II (MHC-II) expression and phagocytosis, and activating autophagy by autophagy inducer trehalose (Tre) can overcome asparaginase-induced immune suppression in macrophages. Our results advance knowledge of the influence of asparaginase on M1 macrophages, and provide an insight into the role of autophagy in asparaginaseinduced immune suppression.

\section{Results}

Asparaginase inhibits phagocytosis and proliferation in M1 macrophages. First, the effect of asparaginase on macrophages phagocytic function was determined in activated Ana-1 and RAW264.7 cells. Phagocytosis is a basic cellular function of macrophages having an important role in innate immunity. ${ }^{31}$ As shown in Figure 1a and Supplementary Figure 1, Ana-1 and RAW264.7 cells stimulated by IFN- $\gamma$ and LPS for $24 \mathrm{~h}$ showed significantly increased phagocytic activity measured as zymosan-Alexa Fluor 488 particles internalization (green fluorescence). However, the macrophage phagocytic function was significantly impaired when treated with asparaginase, indicating the phagocytosis was inhibited by asparaginase in activated Ana-1 and RAW264.7 cells.

Second, we labeled macrophages with carboxyfluorescein succinimidyl ester (CFSE) and investigated the effect of asparaginase on proliferation of Ana-1 and RAW264.7 cells. ${ }^{32}$ As shown in Figure $1 \mathrm{~b}$, at $0 \mathrm{~h}$ in control, Ana-1 and RAW264.7 cells showed a potent fluorescence intensity (right side), and at $24 \mathrm{~h}$ in both control and IFN- $\gamma /$ LPS-treated cells the fluorescence intensity attenuated owing to cell division (left side). After treating with asparaginase, the curve shifted from left to the right as compared with control and IFN- $\gamma /$ LPStreated cells, indicating that asparaginase inhibited proliferation of macrophages.

Finally, we investigated the effect of asparaginase on cell cycle distribution in Ana-1 and RAW264.7 cells. Cell cycle is a repeating series of events that take place in a cell leading to its division and DNA replication to produce two daughter cells. As shown in Figure 1c, upon asparaginase treatment, Ana-1 and RAW264.7 cells at G1 phase increased with reduced cells at $S$ phase when compared with IFN- $\gamma$ and LPS-stimulated macrophages, indicating asparaginase could induce $\mathrm{G} 1$ arrest to decelerate the cell cycle, and prevent the cells from entering the $S$ phase and proliferating.

These results demonstrate that asparaginase inhibits phagocytosis and proliferation in M1 macrophages, and support our hypothesis that asparaginase might influence the function of M1 macrophages.

Asparaginase inhibits ROS and NO generation in M1 macrophages. Activated macrophages generally have high rate of free radical secretion (superoxide, NO), which helps to destroy foreign material. We determined the level of ROS and $\mathrm{NO}$ in asparaginase-treated Ana-1 and RAW264.7 cells to investigate whether asparaginase influences free radical secretion in macrophages. First of all, Ana-1 and RAW264.7 cells stimulated with IFN- $\gamma$ and LPS either alone or in combination with asparaginase for $24 \mathrm{~h}$ were stained by Hoechst 33342 (nucleus) and Mito sox (ROS), and followed by measurement of fluorescence of Ana-1 and RAW264.7 cells using confocal microscopy. Figure $2 \mathrm{a}$ and Supplementary Figure 2 showed that activated Ana-1 and RAW264.7 cells exhibited potent intensity of red fluorescence, which indicates high level of ROS, whereas, when treated with asparaginase, the fluorescence intensity reduced obviously. To further determine the ROS level in asparaginase-treated Ana-1 and RAW264.7 cells, we used 20,70-dichlorofluorescein diacetate (DCFH-DA) assay. As expected, we indeed found a significant reduction of ROS level, expressed by relative fluorescence intensity, in macrophages incubated with asparaginase for $24 \mathrm{~h}$ when compared with activated macrophages (Figure $2 \mathrm{~b}$ ). Next, Griess reagent was used to detect the NO level in Ana-1 and RAW264.7 cells. As shown in Figure $2 \mathrm{c}, \mathrm{IFN}-\gamma$ and LPS stimulation significantly increased the production of $\mathrm{NO}$ by $\sim 1.6$-fold when compared with the untreated cells. However, the IFN- $\gamma$ and LPS-induced NO production reduced in the Ana1 and RAW264.7 cells when treated with asparaginase $(P<0.05)$, indicating asparaginase restrained NO production in IFN- $\gamma$ and LPS-stimulated macrophages.

These observations strongly suggest that asparaginase inhibits ROS and NO generation in M1 macrophages.

The cytokine secretion and MHC-II expression are inhibited by asparaginase in M1 macrophages. The proinflammatory cytokine production is one of the most important functions of activated macrophages by inflammatory stimulation. The effect of asparaginase on two pro-inflammatory cytokines, tumor necrosis factor $a$ (TNF- $a$ ) and IL-6, was investigated in IFN- $\gamma$ and LPS-stimulated macrophages. As depicted in Figure 3a, in Ana-1 macrophages, incubation with IFN- $\gamma$ and LPS alone for $24 \mathrm{~h}$ significantly increased the secretion of TNF- $a$ and IL- 6 by 2.8 and 6.4-fold, respectively, compared with non-treated cells as measured by enzymelinked immunosorbent assay (ELISA) kit. However, the secretion of TNF- $a$ and IL- 6 decreased when treated with asparaginase $(P<0.01)$. In RAW264.7 macrophages, 
a

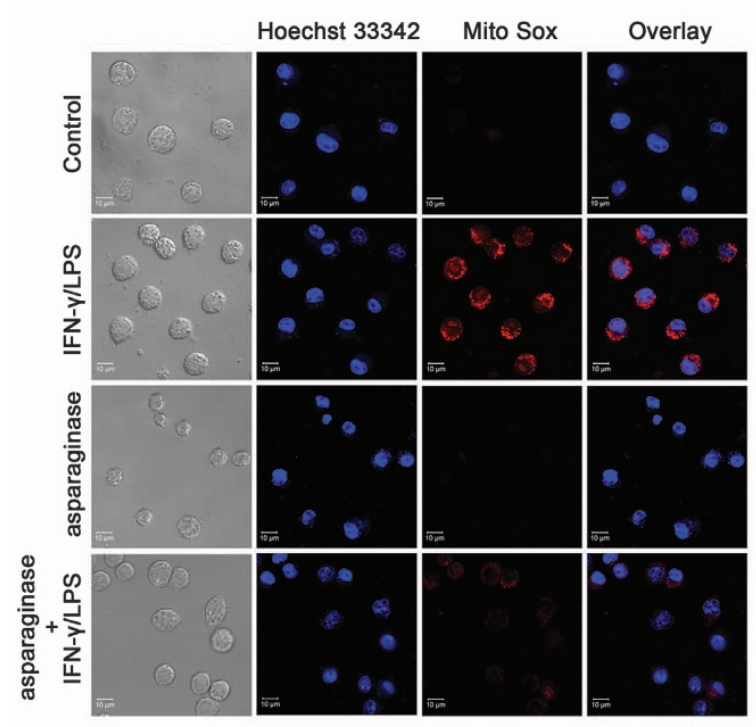

b

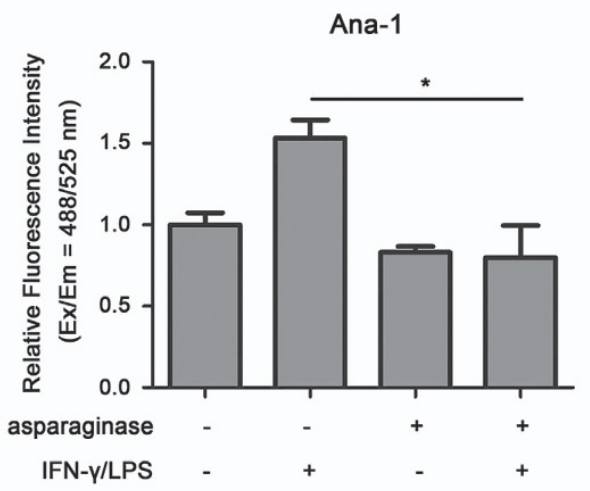

c

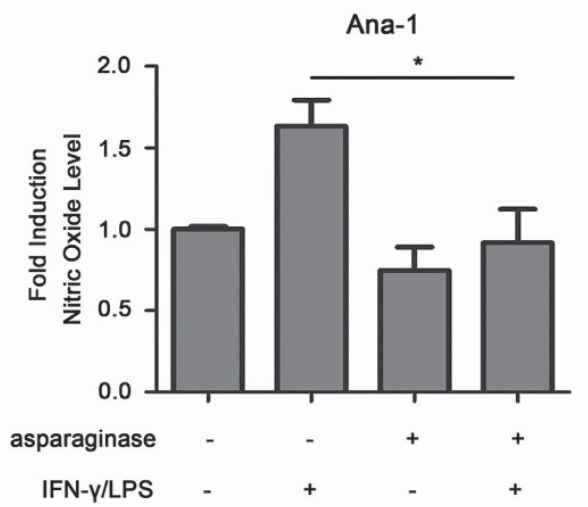

RAW264.7

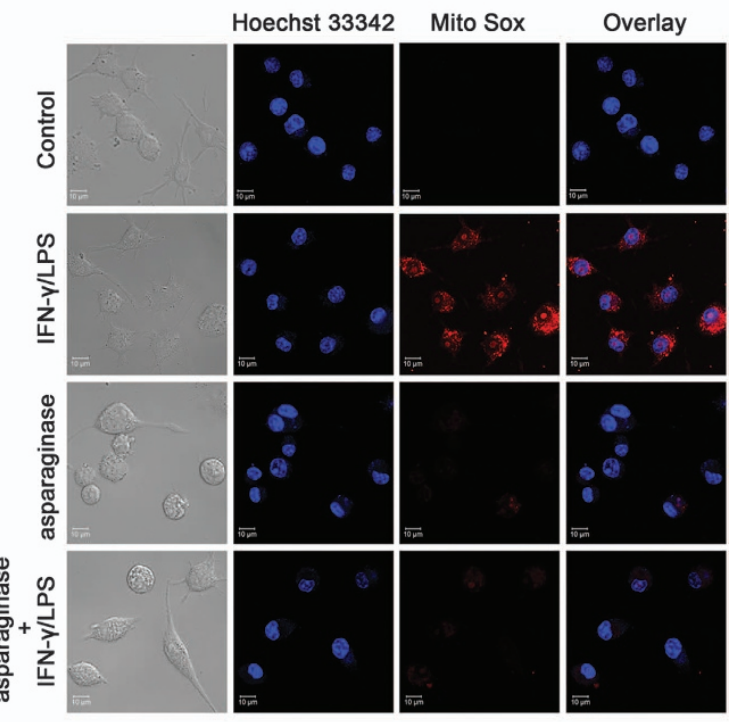

RAW264.7

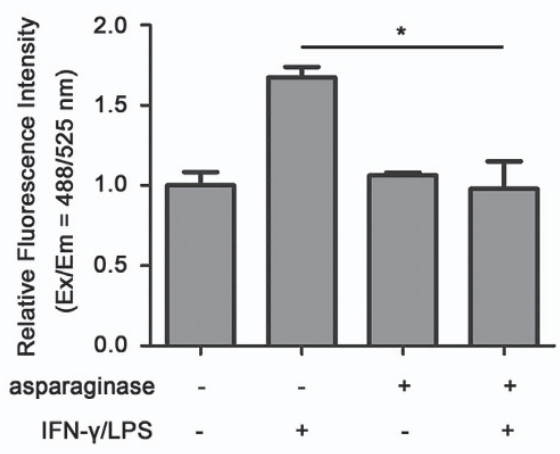

RAW264.7

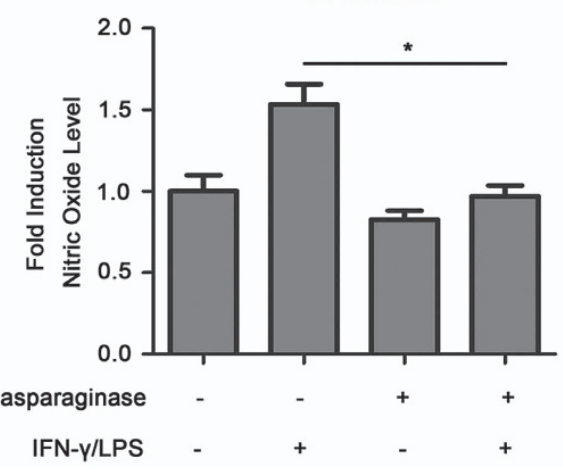

Figure 2 ROS and NO generation are inhibited by asparaginase in Ana-1 and RAW264.7 cells. (a-c) Ana-1 and RAW264.7 cells were treated with 300 IU/ml IFN- $\gamma$ and $200 \mathrm{ng} / \mathrm{ml}$ LPS, either alone or in combination with $0.1 \mathrm{lU} / \mathrm{ml}$ asparaginase for $24 \mathrm{~h}$. (a) Cells were stained with Mito Sox red dye (ROS) and examined by confocal fluorescent microscopy. (b) Intracellular ROS levels in macrophages were determined by relative fluorescence intensity. (c) NO production was assessed by Griess reagent, microplate reader was used to determine the OD value. Results were represented as mean \pm S.D. $\left({ }^{*} P<0.05\right)$

stimulation with IFN- $\gamma$ and LPS for $24 \mathrm{~h}$ significantly increased the production of TNF- $a$ and IL- 6 by 2.5 and 4.1 -fold, respectively, and treatment with $0.1 \mathrm{IU} / \mathrm{ml}$ asparaginase in macrophages decreased the secretion of TNF- $a$ and IL-6 $(P<0.01)$ (Figure 3b). Similarly, in peritoneal macrophages, incubation with IFN- $\gamma$ and LPS alone for $24 \mathrm{~h}$ significantly increased the secretion of TNF- $\alpha$ and IL- 6 by 2.7 and 5.5 -fold, respectively, and treatment with $0.1 \mathrm{IU} / \mathrm{ml}$ asparaginase decreased the secretion of TNF- $a$ and IL-6 (Supplementary Figure 3) $(P<0.01)$.

MHC-II is constitutively expressed in the surface of DCs, monocytes and macrophages. As MHC-II presents antigens to 
a

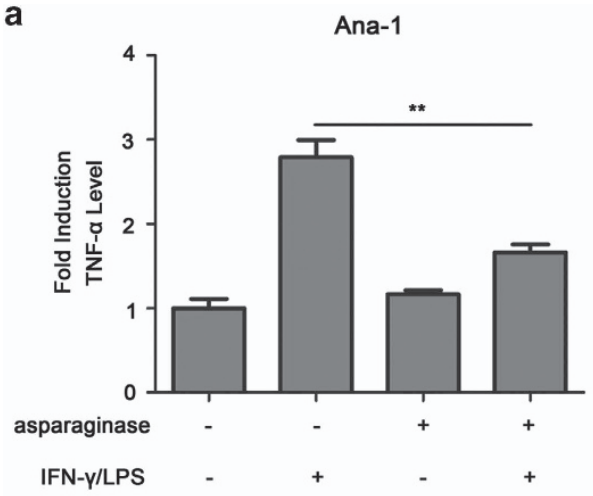

b

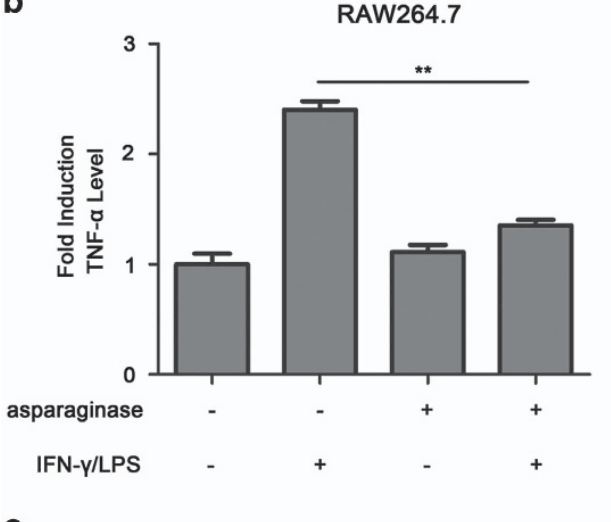

C

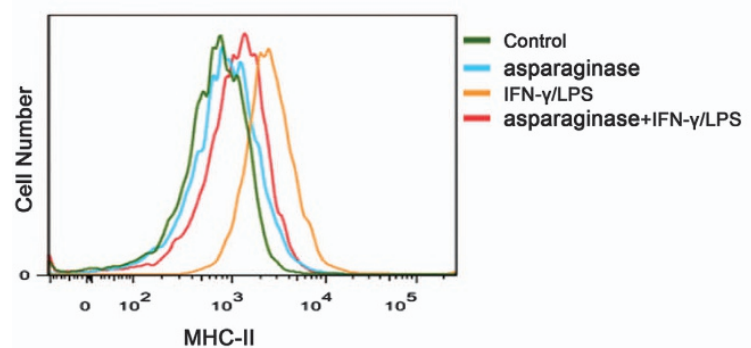

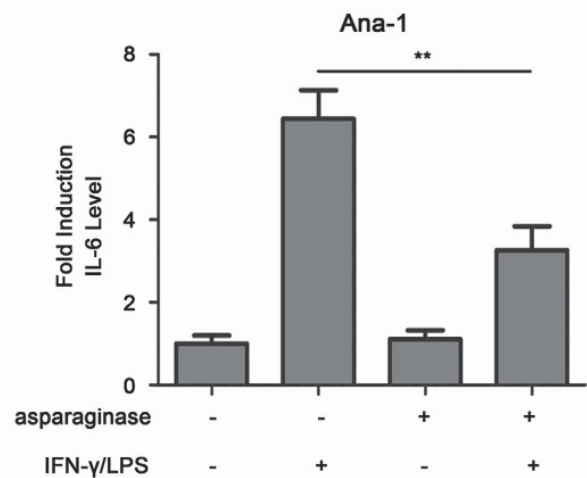

RAW264.7

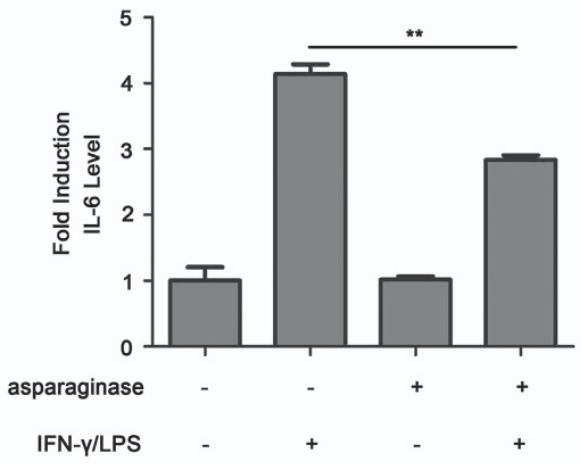

RAW264.7

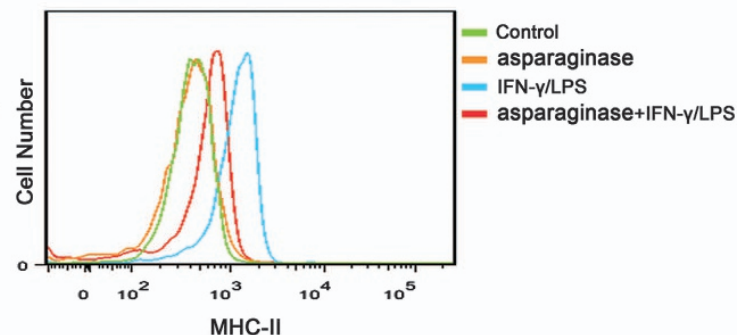

Figure 3 Cytokine production and MHC-II expression are inhibited by asparaginase in Ana-1 and RAW264.7 cells. (a-c) Ana-1 or RAW264.7 cells were treated with $300 \mathrm{IU} / \mathrm{ml} \mathrm{IFN}-\gamma$ and $200 \mathrm{ng} / \mathrm{ml} \mathrm{LPS}$, in the presence or absence of $0.1 \mathrm{IU} / \mathrm{ml}$ asparaginase for $24 \mathrm{~h}$. (a) The content of TNF- $\alpha$ and IL- 6 in the supernatants of Ana- 1 cells was measured by ELISA. (b) The levels of TNF- $\alpha$ and IL-6 in the culture medium of RAW264.7 cells was measured by ELISA. (c) MHC-II expression of Ana-1 and RAW264.7 cells was detected by flow cytometer. Results were represented as mean \pm S.D. $\left({ }^{\star \star} P<0.01\right)$

$\mathrm{CD}^{+} \mathrm{T}$ cells, it is the main regulator of the immune response. ${ }^{33,34}$ We cannot help asking whether asparaginase inhibits surface expression of $\mathrm{MHC}-\mathrm{Il}$ in macrophages. As shown in Figure 3c, stimulation of Ana-1 and RAW264.7 cells with IFN- $\gamma$ and LPS resulted in increased surface expression of MHC-II. However, when treated with asparaginase, MHC-II surface expression in activated Ana-1 and RAW264.7 cells significantly decreased, indicating asparaginase inhibited intracellular presentation of antigenic peptides to T cells via MHC-II.

Together, these results demonstrate that asparaginase inhibits cytokine secretion and MHC-II expression in M1 macrophages.

Autophagy is downregulated in M1 macrophages during asparaginase treatment. Recent studies have demonstrated that autophagy has a beneficial role in the function of macrophages as a major regulator of immune responses such as clearance of intracellular pathogens, antigen presentation and excessive production of inflammatory cytokines. $^{35,36}$ To examine whether asparaginase influences autophagic response in activated Ana-1 and RAW264.7 cells, several well-established methods were performed to detect autophagosomes formation. First of all, we examined the intracellular morphologic change of Ana-1 and RAW264.7 cells using transmission electron microscopy (TEM). Figure $4 \mathrm{a}$ showed increased accumulation of doublemembrane-enclosed autophagosomes in both Ana-1 and RAW264.7 cells after IFN- $\gamma$ and LPS stimulation for $24 \mathrm{~h}$, whereas the number of autophagic vacuoles decreased when treated with asparaginase. Next, we used a Cyto-ID Green dye autophagy detection kit to detect autophagic vacuoles 
a

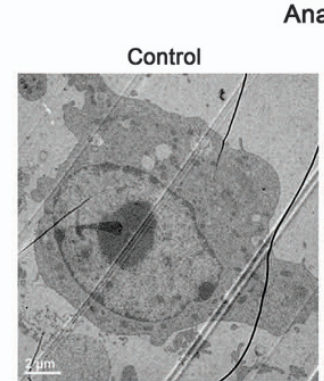

asparaginase+IFN-y/LPS

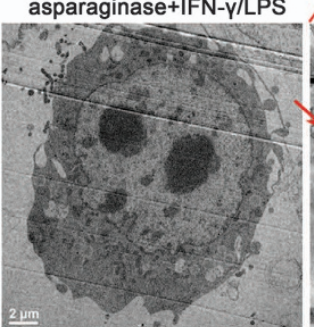

2um

b

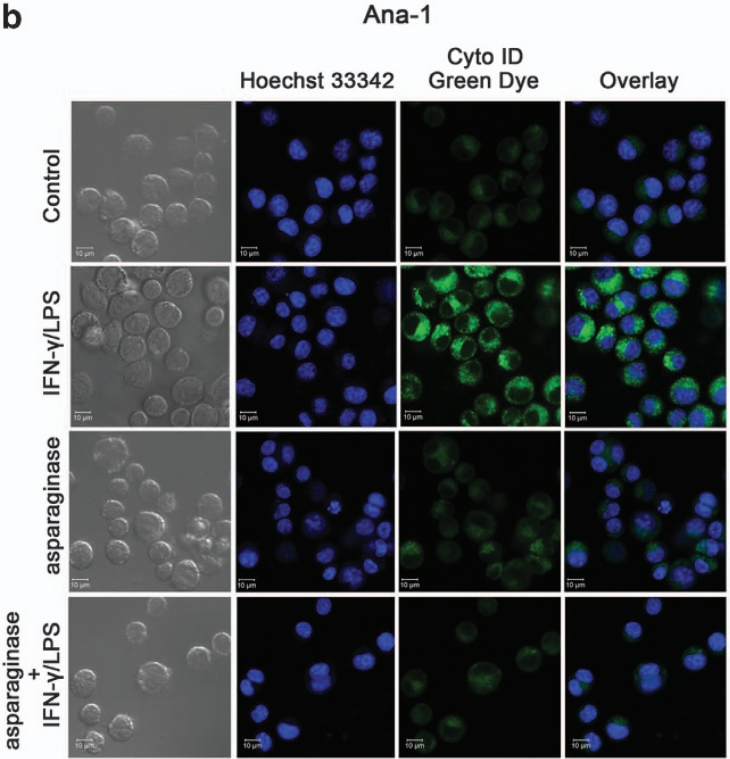

C
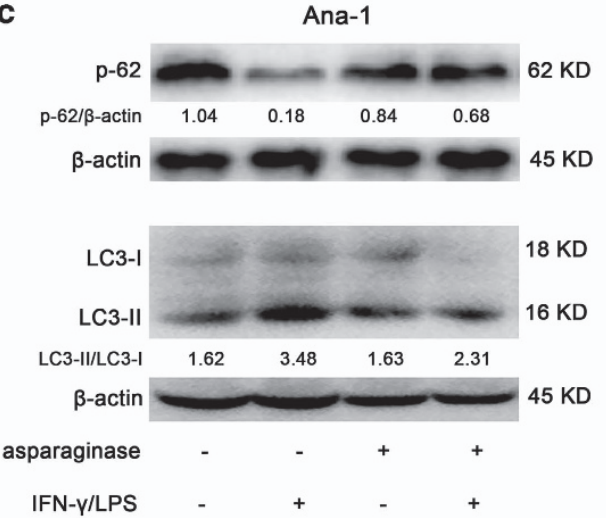

RAW264.7

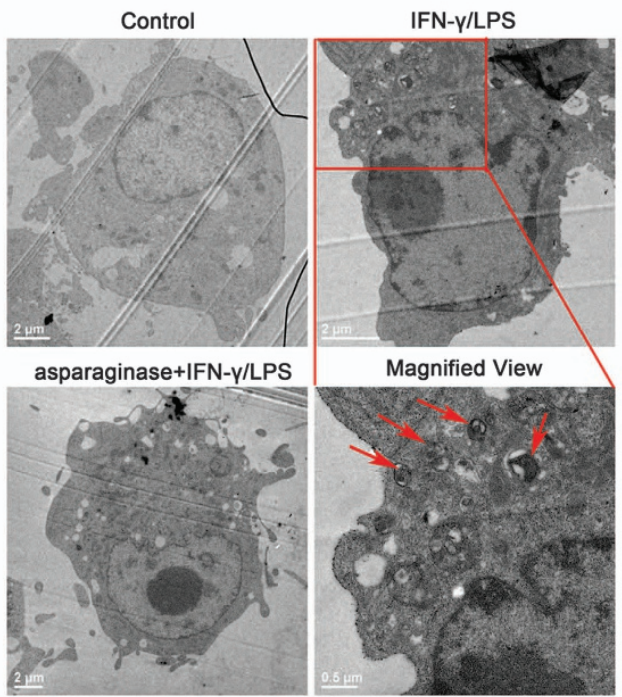

RAW264.7

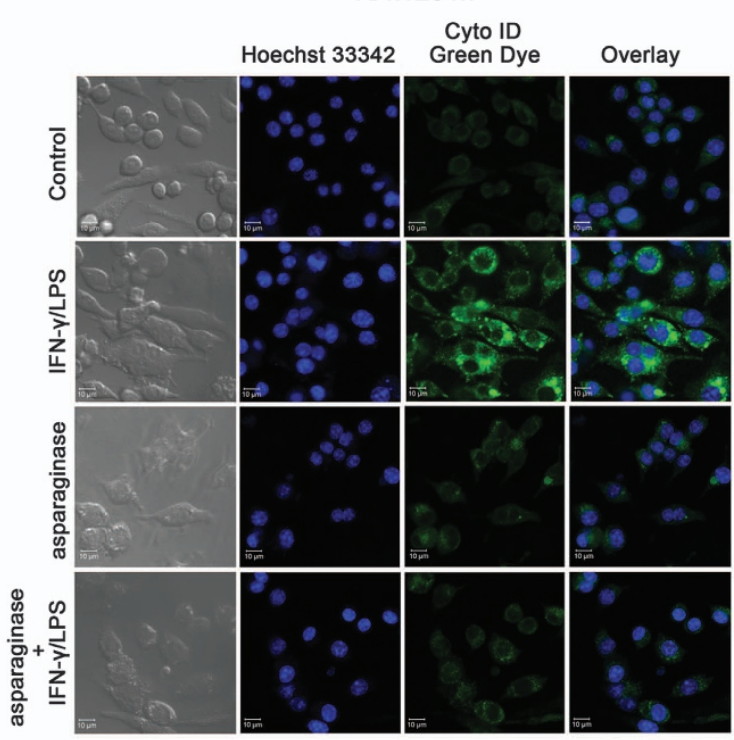

RAW264.7
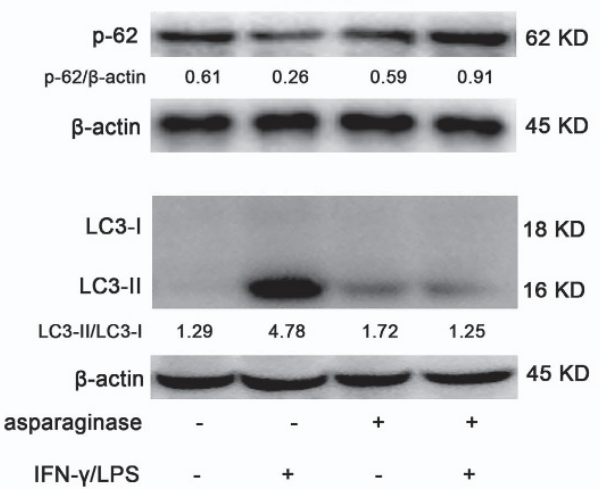

Figure 4 Autophagy is downregulated by asparaginase in Ana-1 and RAW264.7 cells. (a-c) Ana-1 and RAW264.7 cells were treated with $300 \mathrm{IU} / \mathrm{ml} \mathrm{IFN-} \gamma$ and $200 \mathrm{ng} / \mathrm{ml}$ LPS, either alone or in combination with $0.1 \mathrm{IU} / \mathrm{ml}$ asparaginase for $24 \mathrm{~h}$. (a) TEM was employed to detect the autophagosomes ('red arrows': autophagosomes) in Ana-1 and RAW264.7 cells. (b) Macrophages were stained with Cyto-ID Green autophagy dye and examined by confocal fluorescent microscopy. (c) Autophagy-associate protein LC3-I/II and p62 were detected by western blot analysis. Densitometric values were quantified using the ImageJ software, and the data represented mean of three independent experiments 
a

Ana-1
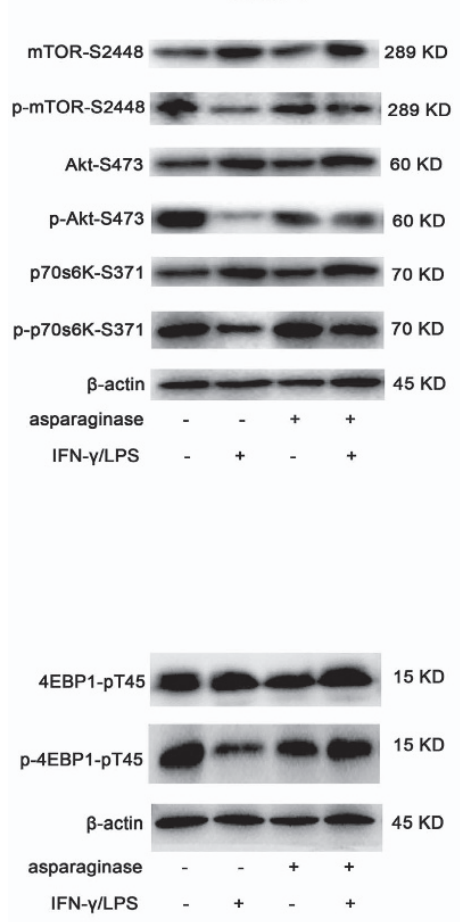

C

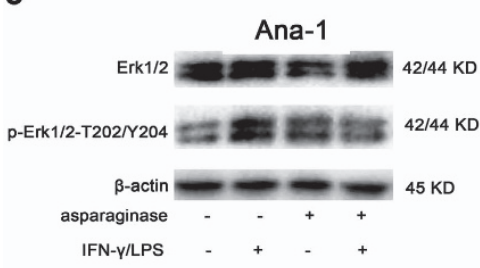

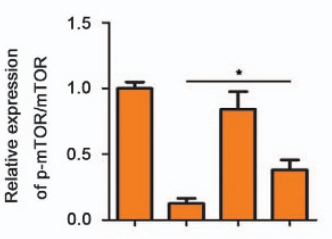
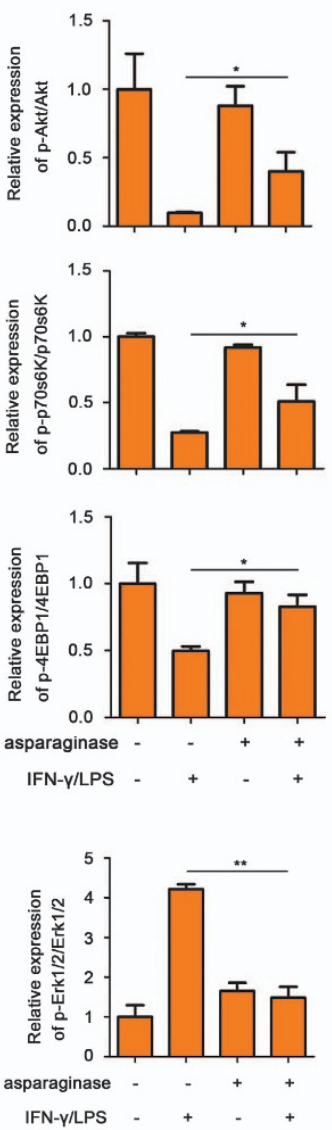

b
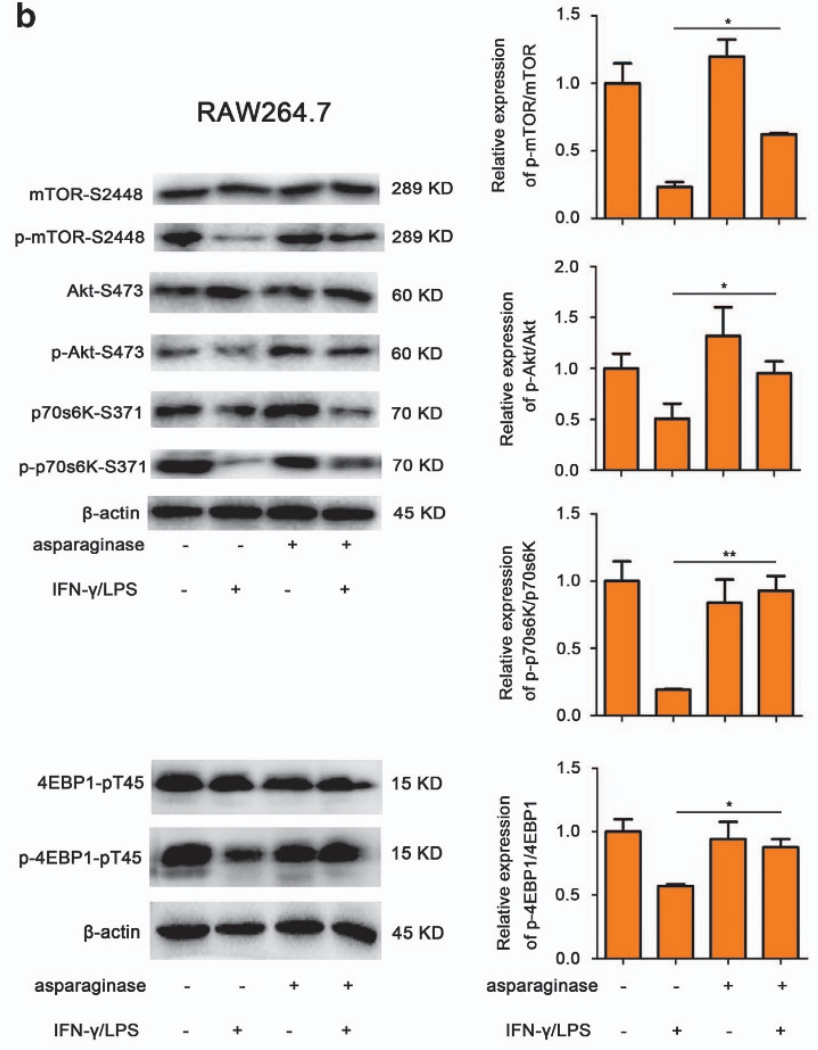

d

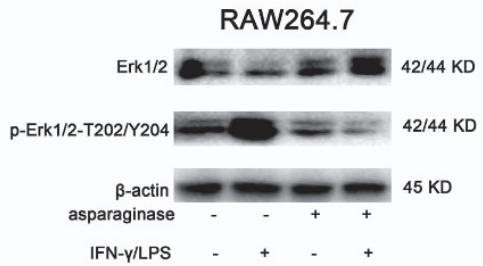

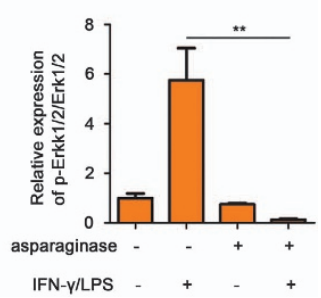

Figure 5 Asparaginase downregulates autophagy by activating Akt/mTOR and inhibiting Erk1/2 signaling pathway. (a-d) Ana-1 and RAW264.7 cells were treated with $300 \mathrm{IU} / \mathrm{ml} \mathrm{IFN}-\gamma$ and $200 \mathrm{ng} / \mathrm{ml}$ LPS, either alone or in combination with $0.1 \mathrm{IU} / \mathrm{ml}$ asparaginase for $24 \mathrm{~h}$. (a) The expression level of mTOR, p-mTOR, Akt, p-Akt, p70s6K, p-p70s6K, 4EBP1, and p-4EBP1 in Ana-1 cells were analyzed by western blot. Quantification of p-mTOR/mTOR, p-Akt/Akt, p-p70s6K/p70s6K, and p-4EBP1/4EBP1 ratios in different groups were presented in bar graphs. (b) The expression of mTOR, p-mTOR, Akt, p-Akt, p70s6K, p-p70s6K, 4EBP1, and p-4EBP1 in RAW264.7 cells were analyzed by western blot. Quantification of p-mTOR/mTOR, p-Akt/Akt, p-p70s6K/p70s6K, and p-4EBP1/4EBP1 ratios in different groups were presented in bar graphs. (c) Western blot was performed to analyze the protein Erk1/2 and p-Erk1/2 in Ana-1 cells. Quantification of $p$-Erk1/2/Erk1/2 ratios in different groups were presented in bar graphs. (d) Western blot was performed to analyze the protein Erk1/2 and p-Erk1/2 in RAW264.7 cells. Quantification of p-Erk1/2/Erk1/2 ratios in different groups were presented in bar graphs. Densitometric values were quantified using the ImageJ software and normalized to control. The values of control were set to 1 . Results were represented as mean \pm S.D. $\left({ }^{\star} P<0.05,{ }^{* \star} P<0.01\right.$ )

with fluorescence microscopy. Ana-1 and RAW264.7 cells, stimulated with IFN- $\gamma$ and LPS for $24 \mathrm{~h}$, displayed more green fluorescence than that in the non-treated cells. In contrast, when incubated with $0.1 \mathrm{IU} / \mathrm{ml}$ asparaginase, the activated Ana-1 and RAW264.7 cells showed limited specific green fluorescence (Figure $4 \mathrm{~b}$ and Supplementary Figure 4). Finally, we examined the conversion of microtubuleassociated protein LC3 (known as autophagy-related protein) and Sequestosome 1 (SQSTM1/p62) (a substrate of autophagy), to assess autophagy levels in Ana-1 and RAW264.7 cells through western blot analysis. Autophagosome formation involves the conversion of LC3 from the cytosolic LC3-I to the autophagosome-associated LC3-II form and decrease of p62 levels. ${ }^{21}$ As shown in Figure $4 \mathrm{c}$, IFN- $\gamma$ and LPS- stimulated macrophages exhibited an obvious conversion of endogenous LC3-I to LC3-II and decrease in protein levels of p62, whereas combined treatment with $0.1 \mathrm{IU} / \mathrm{ml}$ asparaginase downregulated the LC3-II conversion and increased p62 levels in activated macrophages.

Together, these results indicate that asparaginase downregulates the formation of autophagosomes in M1 macrophages.

Asparaginase downregulates autophagy by activating Akt/mTOR and suppressing Erk1/2 signaling pathway in M1 macrophages. We further explored the underlying mechanism of asparaginase-induced autophagy downregulation in Ana-1 and RAW264.7 cells. The mammalian target 
of rapamycin (mTOR), an evolutionarily conserved serine/ threonine kinase, serves as not only a key positive regulator of protein synthesis and cell growth but also a major negative regulator of autophagy in eukaryotic cells. ${ }^{37}$ MTOR can be phosphorylated by upstream protein phosphorylated-Akt to form p-mTOR-S2448, which inhibits autophagy. Moreover, a

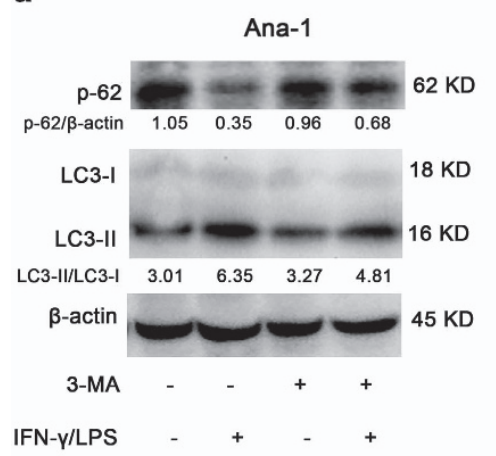

C

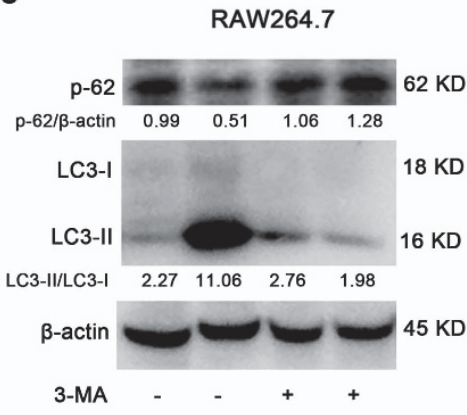

IFN-y/LPS b

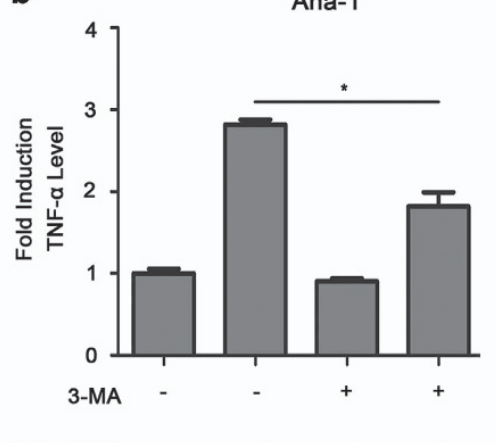

IFN-y/LPS

d

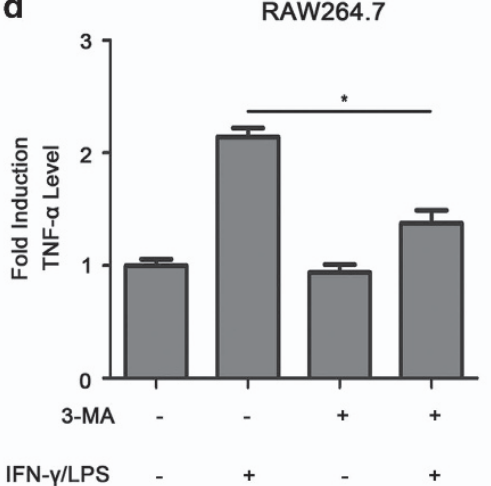

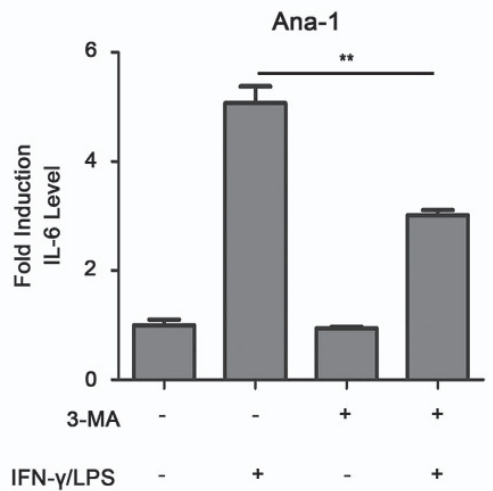

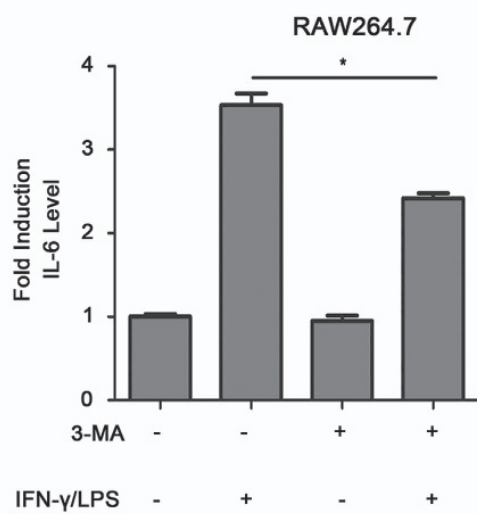

e

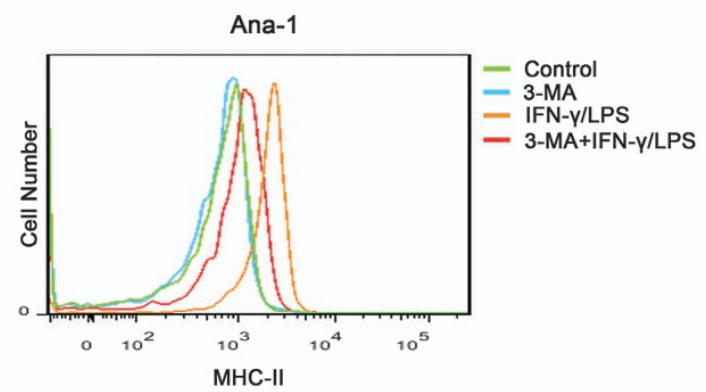

f

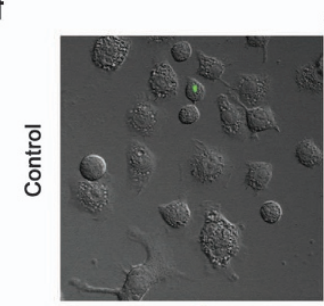

Ana-1

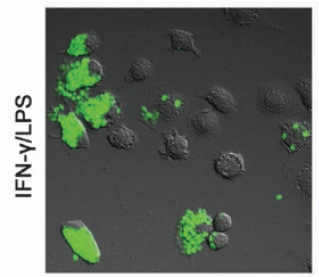

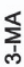
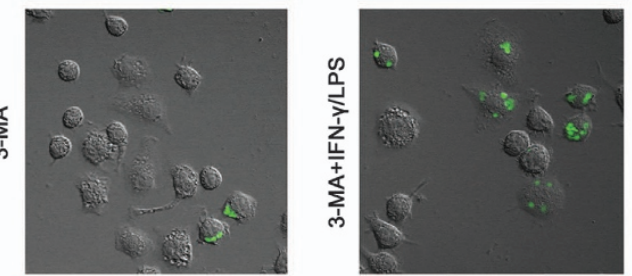

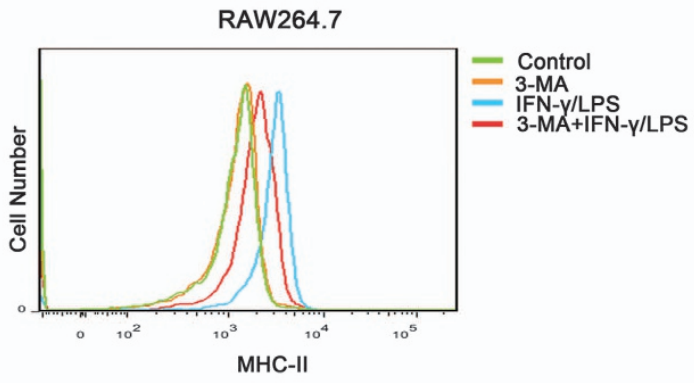

RAW264.7
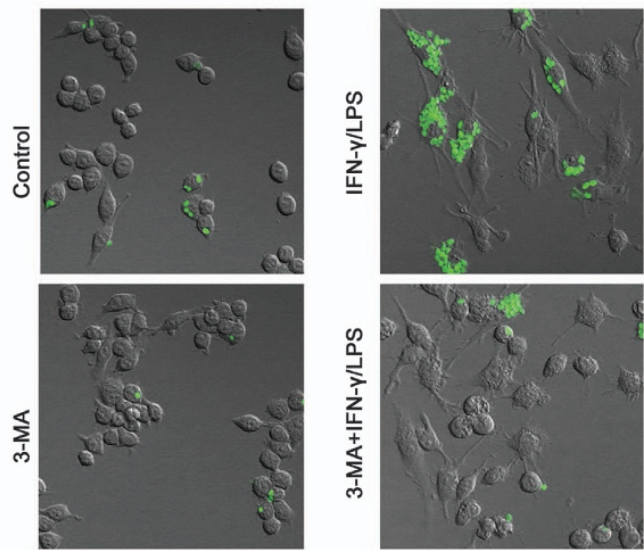
mTOR downregulates autophagy by mediating protein translation and cell growth through the phosphorylation of two key protein targets, eukaryotic initiation factor 4E-binding protein 1 (4EBP1) and polypeptide 1 ribosomal protein S6 kinase-1 (p70s6K). ${ }^{38}$ Our experiments discovered that asparaginase-treated Ana-1 and RAW264.7 cells expressed high level of protein p-mTOR-S2448 when compared with IFN- $\gamma$ and LPS-activated macrophages. Besides, asparaginase efficiently increased the phosphorylation of Akt (upstream protein of mTOR), p70s6K and 4EBP1 (two downstream substrates of mTOR) (Figures $5 a$ and $b$ ). Moreover, after treating with asparaginase, the ratios of p-mTOR/mTOR, p-Akt/Akt, p-p70s6K/ p70s6K, and p-4EBP1/4EBP1 increased as compared with IFN- $/$ /LPStreated macrophages $(P<0.05, P<0.01)$, indicating mTOR activity was activated in macrophages after exposure to asparaginase.

Because extracellular signal-regulated kinase (Erk1/2) has been shown to regulate expression of autophagy and lysosomal genes, ${ }^{38}$ we then analyzed whether asparaginase modulated the expression of Erk1/2 pathway-related protein in Ana-1 and RAW264.7 cells. Figures 5c and d showed that the expression of $p$-Erk1/2 in the macrophages stimulated with IFN- $\gamma$ and LPS was significantly higher than that in nonstimulated cells. The addition of asparaginase alone to macrophages had little influence on $\mathrm{p}$-Erk1/2 expression. However, it significantly weakened IFN- $\gamma$ and LPS-induced p-Erk1/2 expression. Furthermore, after treating with asparaginase, the ratios of $\mathrm{p}$-Erk1/2/Erk $1 / 2$ decreased as compared with IFN- $\gamma$ and LPS-activated macrophages $(P<0.01)$, indicating Erk1/2 activity was suppressed in macrophages after exposure to asparaginase.

Together, these experiments suggest that asparaginase downregulates autophagy in M1 macrophages by activating Akt/mTOR and suppressing Erk1/2 signaling pathway.

Autophagy has an important role in asparaginaseinduced immune suppression in M1 macrophages. To reveal the role of autophagy in the weakening effects of asparaginase on IFN- $\gamma$ and LPS-induced IL-6, TNF- $a$ secretion, MHC-II expression, and phagocytosis in Ana-1 and RAW264.7 cells, the autophagy inhibitor 3-methyladenine (3-MA) was used in place of asparaginase. 3-MA is a specific inhibitor of PI3K, which inhibits autophagosomes accumulation and inhibits the conversion of LC3-I to LC3-II. Western blot analysis indicated that IFN- $\gamma$ and LPS-induced autophagy was successfully inhibited by 2 mM 3-MA (Figures $6 a$ and c). As shown in Figures $6 \mathrm{~b}, \mathrm{~d}$ and e, and Supplementary Figure 5, at $24 \mathrm{~h}$ after 3-MA treatment, the secretion of TNF- $a$ and IL-6, and the expression of MHC-II in IFN- $\gamma$ and
LPS-stimulated macrophages markedly decreased. We next examined the effect of 3-MA on phagocytosis of macrophages. As shown in Figure $6 f$ and Supplementary Figure 6, inhibition of autophagy by 3-MA suppressed the phagocytosis of activated macrophages, indicating autophagy had an important role in the function of macrophages.

As asparaginase simultaneously inhibited immune function and autophagic response in activated Ana-1 and RAW264.7 cells, and it has been reported that autophagy had a beneficial role in the function of macrophages, we want to know whether activation of autophagy could overcome asparaginaseinduced immune suppression in Ana-1 and RAW264.7 cells. In our following experiments, Tre (an autophagy inducer) was combined with asparaginase to treat IFN- $\gamma$ and LPSstimulated Ana-1 and RAW264.7 cells. Western blot analysis showed that Tre could upregulate the conversion of LC3-II and decrease the levels of p62 compared with asparaginasetreated activated macrophages (Figures 7a and c). Subsequently, we found that in activated Ana-1 and RAW264.7, as well as in peritoneal macrophages, Tre significantly increased the secretion of pro-inflammatory mediators TNF- $a$ and IL-6 compared with asparaginase-treated macrophages $(P<0.05$, $P<0.01$ ) (Figures $7 \mathrm{~b}$ and $\mathrm{d}$ and Supplementary Figure 7 ). In addition, we observed Tre could restore the expression of MHC-II and phagocytosis of Ana-1 and RAW264.7 cells, which inhibited by asparaginase (Figures $7 e$ and $f$ and Supplementary Figure 8).

All of these results suggest that autophagy has an important role in the function of M1 macrophages. Activation of autophagy can overcome asparaginase-induced immune suppression in M1 macrophages.

\section{Discussion}

Erwinia asparaginase is an FDA-approved enzyme drug for treatment of select cancers. Asparaginase administration results in rapid and complete deamination of the amino acid asparagine and, to a lesser extent, glutamine, leading to depletion of asparagine in the plasma. ${ }^{39}$ Despite its application as an essential drug used in all treatment protocols for $\mathrm{ALL}$, asparaginase is associated with a unique set of side effect that limits its clinical outcomes. When asparaginase therapy was introduced in the treatment of cancer it became obvious that this bacteria-derived enzyme had other effects, one of the most significant is immunosuppression, which is regarded to be in association with its glutaminase activity. ${ }^{6}$ Immune cells require substantial amounts of glutamine to sustain its proliferation and functions, whereas all the asparaginases possess some degree of glutaminase activity, which hydrolyzes the amino acid glutamine. ${ }^{40}$

Figure 6 Inhibiting autophagy induces immune suppression in Ana- 1 and RAW264.7 cells. (a-f) Ana- 1 and RAW264.7 cells were treated with 300 IU/ml IFN- $\gamma$ and 200 ng/ml LPS, in the presence or absence of 2 mM 3-MA for $24 \mathrm{~h}$. (a) Autophagy-associated protein LC3-1/II and p62 were detected by western blot analysis in Ana-1 cells. Densitometric values were quantified using the ImageJ software, and the data represented mean of three independent experiments. (b) The content of TNF- $\alpha$ and IL- 6 in the supernatants of Ana- 1 cells were measured by ELISA. (c) Autophagy-associated protein LC3-I/II and p62 were detected by western blot analysis in RAW264.7 cells. Densitometric values were quantified using the ImageJ software, and the data represented mean of three independent experiments. (d) The level of TNF- $\alpha$ and IL-6 in the culture medium of RAW264.7 cells were measured by ELISA. (e) The expression of MHC-II in Ana-1 and RAW264.7 cells were detected by flow cytometer. (f) The cells were incubated with zymosan particles for another $2 \mathrm{~h}$, and analyzed by confocal fluorescent microscopy. Results were represented as mean \pm S.D. $\left({ }^{*} P<0.05,{ }^{\star *} P<0.01\right)$ 
Previous studies have reported the inhibition effect of asparaginase on blastogenesis and proliferation of $\mathrm{T}$ cell, and expression of T-cell receptor. ${ }^{11,12}$ However, its effects on macrophages functions, especially the underlying molecular mechanism, are still not fully understood. Macrophages are phagocytic immune cells that reside in most tissues and thus a

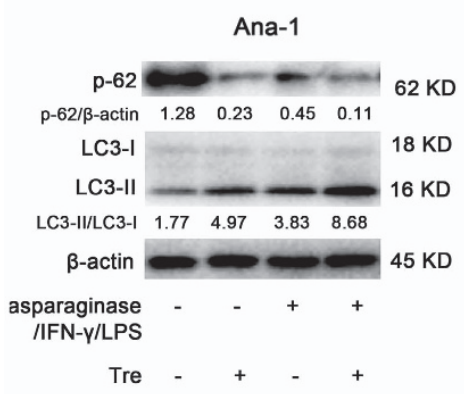

c

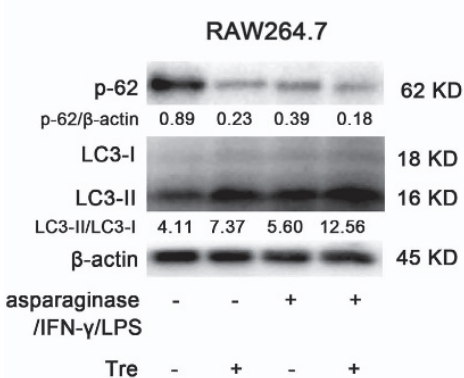

e

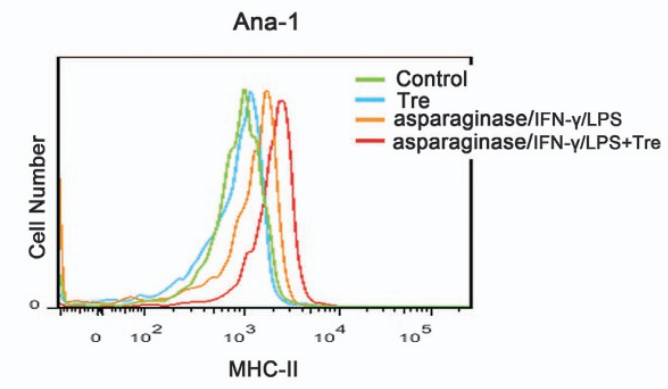

f

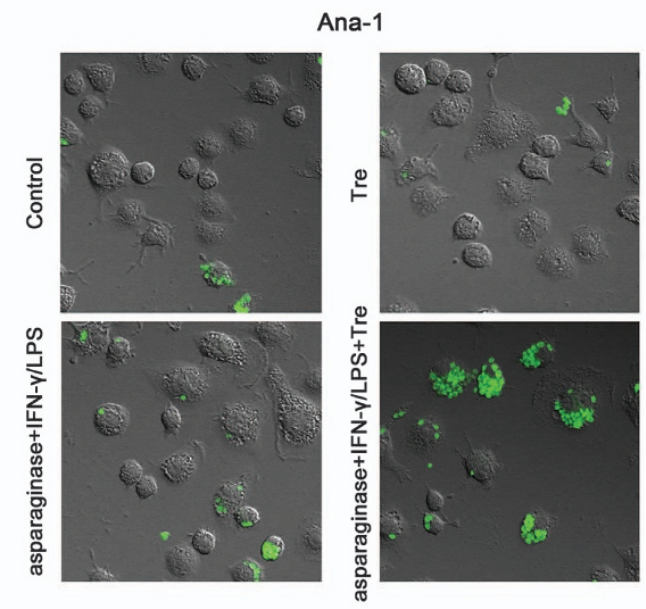

b

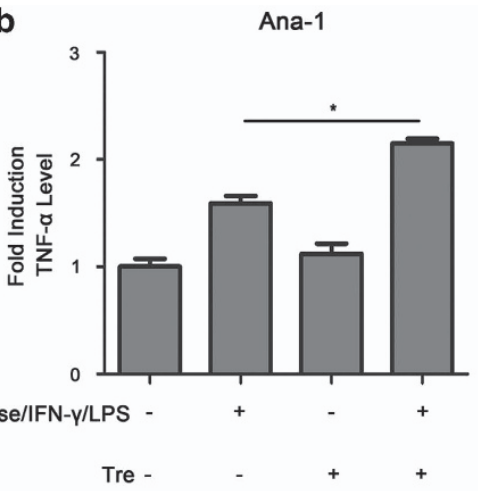

d

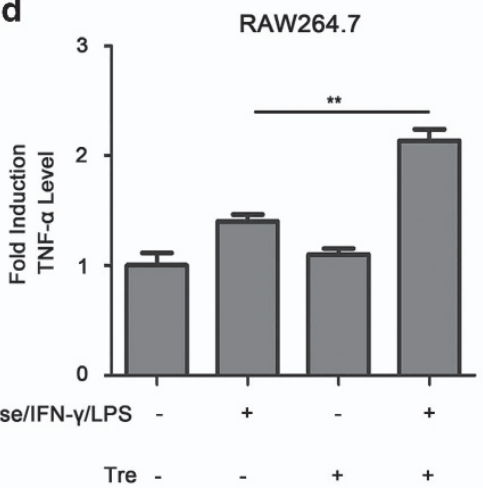

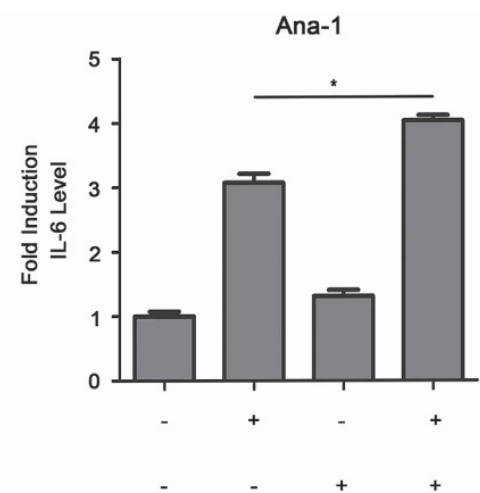

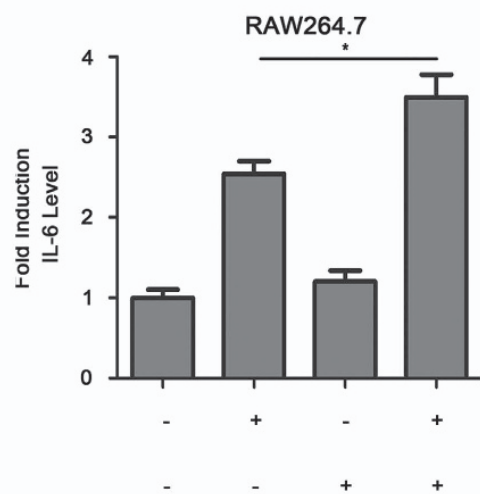

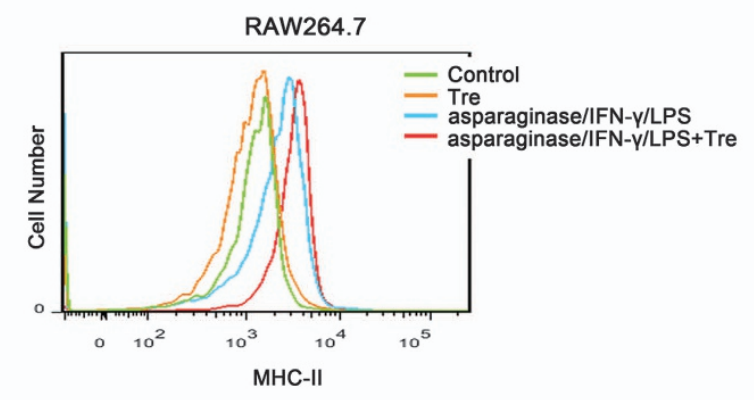

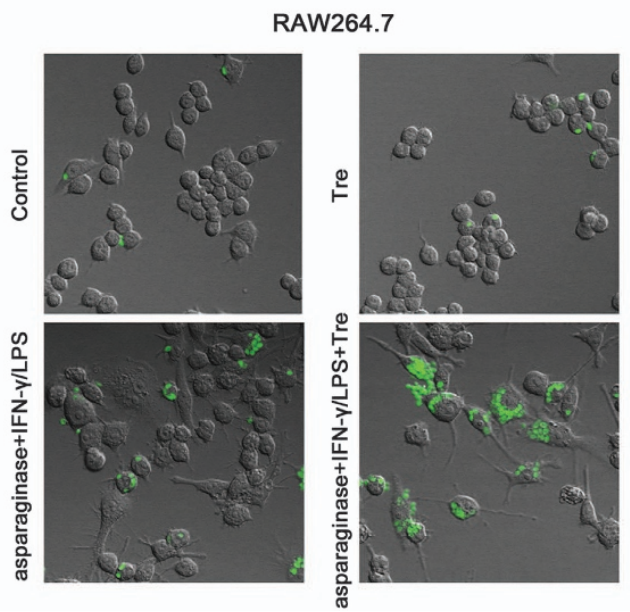


constitute the first line of host defense, and participate in all kinds of the progress of inflammatory diseases, such as atherosclerosis, bacterial and virus infection, obesity-induced insulin resistance, and diabetes. ${ }^{28,30,41,42}$ They are metabolically active cells characterized by high levels of phagocytosis, cytokine secretion, free radical secretion, and antigen presentation-related molecular expression. All of these processes constitute the overall function of the macrophage destroying foreign material via exposure to free radicals, antigen presentation to T-lymphocytes via MHC-II molecules and activation of lymphocyte subpopulations by cytokine. ${ }^{17,43}$

To discover the effect of asparaginase on macrophage function, we first adopted IL-4 to activate macrophages to generate M2 macrophages, and found that asparaginase treatment had no obvious effect on the secretion of IL-10 in M2 macrophages, which suggested that asparaginase did not influence the function of M2 macrophages (Supplementary Figure 9). We then used IFN- $\gamma$ and LPS to stimulate macrophages to generate M1 macrophages, and examined the changes of phagocytosis, proliferation, free radical secretion, pro-inflammatory cytokine secretion, and MHC-II molecule expression in macrophages upon asparaginase treatment. We observed that asparaginase significantly impaired macrophage phagocytic function and induced G1 arrest to prevent the cells from proliferating. Through confocal, DCFH-DA assay and Griess reagent assay, we also found that ROS and NO generation in activated Ana-1 and RAW264.7 cells decreased, indicating that asparaginase disturbed free radical secretion function of macrophage. Moreover, the results of ELISA and flow cytometer manifested that the secretion of two pro-inflammatory cytokine, TNF- $a$ and IL-6, and the expression of antigen presentation molecule MHC-II were all downregulated. These results are in agreement with previous reports that enzyme-induced glutamine depletion restrained $\mathrm{MHC}-\mathrm{Il}$ expression, antigen presentation and phagocytosis, and LPS-stimulated TNF- $a$ and IL-6 production in murine macrophage was also dependent upon the availability of extracellular glutamine., , $^{\circ}$

Our further experiment proved that asparaginase treatment had no obvious effect on the number of macrophages, indicating the immune suppression effect of asparaginase was not by reducing the number of macrophages (Supplementary Figure 10). In recent years, a growing body of evidence demonstrates the important role of autophagy in innate immunity, inflammatory responses, and adaptive immunity. ${ }^{25,44}$ These findings inspire us to reveal whether asparaginase affects autophagic response of macrophages, furthermore, whether asparaginase induces macrophage immune suppression by influencing autophagy. In our experiments, we indeed observed that asparaginase inhibited autophagic response in activated Ana-1 and RAW264.7 cells as evidenced by the less formation of autophagosomes through TEM analysis, downregulation of autophagy-related protein LC3-II through western blot analysis, and decreased number of autophagy-like vacuoles through confocal microscopy analysis.

We also discovered the underlying molecular mechanisms of asparaginase-induced autophagy inhibition. The Akt/mTOR and Erk1/2 signaling pathway is two of the major pathways regulating autophagy in eukaryotic cells. ${ }^{45}$ MTOR acts as a major negative regulator of autophagy, whereas Erk $1 / 2$ positively regulates expression of autophagy genes. ${ }^{46,47}$ In our study, western blot analysis showed that mTOR activity was activated in macrophages by asparaginase as evidenced by increased phosphorylation of mTOR, upstream protein Akt, and two downstream substrates p70s6K and 4EBP1, meanwhile Erk1/2 signaling pathway was suppressed evidenced by decreased $p$-Erk1/2 expression. We came to a conclusion that asparaginase inhibited autophagy in macrophages by activating Akt/mTOR and suppressing Erk1/2 signaling pathway.

Based on above experiments, we demonstrate that asparaginase not only suppresses immune function but also inhibits autophagic response in activated macrophages. In consideration of the importance and complexity of autophagy in immune system, ${ }^{48,49}$ it is necessary to elucidate the role of autophagy in asparaginase-induced immune suppression of macrophages. We first used autophagy inhibitor 3-MA to replace asparaginase, and examined its effect on the function of macrophages including phagocytosis, IL-6 and TNF- $a$ secretion and MHC-II expression. As a result, the same effect was achieved by 3-MA. Subsequently, an autophagy inducer Tre was adopted in combination with asparaginase to treat activated macrophages. It was very inspiring that overcoming asparaginase-induced autophagy inhibition by Tre restored the capacity of phagocytosis, IL- 6 and TNF- $a$ secretion and $\mathrm{MHC}-\mathrm{Il}$ expression in macrophages. These results suggest a key role of autophagy in asparaginase-induced immune suppression in macrophages.

In conclusion, our present study demonstrates that asparaginase disturbes the function of macrophages including phagocytosis, proliferation, free radical secretion, cytokine secretion, and $\mathrm{MHC}-\mathrm{Il}$ molecule expression, thus induces immune suppression. Moreover, asparaginase inhibits autophagy in macrophages by activating Akt/mTOR and suppressing Erk1/2 signaling pathway. Further investigations suggest that asparaginase induces macrophage immune suppression through influencing autophagy, and combined treatment with autophagy inducer can reverse asparaginase-induced

Figure 7 Activating autophagy overcomes asparaginase-induced immune suppression in Ana-1 and RAW264.7 cells. (a-f) Ana-1 and RAW264.7 cells were treated with $300 \mathrm{lU} / \mathrm{ml} \mathrm{IFN}-\gamma, 200 \mathrm{ng} / \mathrm{ml} \mathrm{LPS}$, and $0.1 \mathrm{lU} / \mathrm{ml}$ asparaginase, either alone or in combination with $25 \mu \mathrm{M}$ Tre for $24 \mathrm{~h}$. (a) Autophagy-associated protein LC3-I/II and p62 were detected by western blot analysis in Ana-1 cells. Densitometric values were quantified using the ImageJ software, and the data represented mean of three independent experiments. (b) The content of TNF- $\alpha$ and IL-6 in the supernatants of Ana-1 cells were measured by ELISA. (c) Autophagy-associated protein LC3-I/II and p62 were detected by western blot analysis in RAW264.7 cells. Densitometric values were quantified using the ImageJ software, and the data represented mean of three independent experiments. (d) The level of TNF- $\alpha$ and IL-6 in the culture medium of RAW264.7 cells were measured by ELISA. (e) MHC-II expression of Ana-1 and RAW264.7 cells were detected by flow cytometer. (f) The cells were incubated with zymosan particles for another $2 \mathrm{~h}$, and analyzed by confocal fluorescent microscopy. Results were represented as mean \pm S.D. $\left({ }^{\star} P<0.05,{ }^{* *} P<0.01\right)$ 
immune suppression. Our research highlights the important role of autophagy in asparaginase-induced immune suppression in macrophages.

\begin{abstract}
Materials and Methods
Materials. Asparaginase (derived from Erwinia) was purchased from Baiyunshan Mingxing Pharmaceutical Co., Ltd. (Guangzhou, Guangdong Province, China). The autophagy inhibitor 3-MA was obtained from EMD Chemicals, Inc. (San Diego, CA, USA). The autophagy inducer Tre was purchased from Sigma-Aldrich (St. Louis, $\mathrm{MO}$, USA). IFN- $\gamma$ was obtained from Cyagen Biosciences Inc. (Guangzhou, Guangdong Province, China). LPS was obtained from Sigma-Aldrich. The antibodies including anti- $\beta$-actin, anti-LC3B, anti-p62, anti-mTOR (Ser2448), antiphospho-mTOR (Ser2448), anti-Akt (Ser473), anti-phospho-Akt (Ser473), antip70S6 Kinase (pS371), anti-p70S6 Kinase Phospho (pS371), anti-4EBP1-pT45, anti-phospho-4EBP1-pT45, anti-phospho-p44/42 MAPK (Erk1/2) (Thr202/Tyr204), and anti-p44/42 MAPK (Erk1/2) were purchased from Cell Signaling Technology (Danvers, MA, USA). The secondary antibodies horseradish peroxidases (HRP)conjugated goat anti-mouse and anti-rabbit immunoglobulin $\mathrm{G}$ were purchased from MR Biotech (Shanghai, China).
\end{abstract}

Cell culture. C57BL/6 male mice were purchased from Shanghai Super-B\&K Laboratory Animal Corp., Ltd. (Shanghai, China). 5\% starch broth was used to stimulated inflammatory peritoneal macrophages in mice for 3 days, then peritoneal macrophages were isolated and cultured in RPMI-1640 containing 10\% heatinactivated fetal bovine serum (FBS) (Invitrogen, San Diego, CA, USA). Murine Ana1 and RAW264.7 cells were purchased from Cell Bank of Chinese Academy of Sciences, Shanghai Branch (Shanghai, China). The cells were cultured in RPMI-1640 or Dulbecco's modified eagle's medium (DMEM) (Invitrogen) containing $10 \% \mathrm{FBS}, 100 \mathrm{U} / \mathrm{ml}$ of penicillin, and $100 \mu \mathrm{g} / \mathrm{ml}$ of streptomycin at $37^{\circ} \mathrm{C}$ in a humidified atmosphere of $5 \% \mathrm{CO}_{2}$ incubator.

Phagocytosis assay. Ana-1 and RAW264.7 cells were plated in glass bottom cell culture dishes (NEST Biotechnology, Jiangsu, China) at a density of $1 \times 10^{5} / \mathrm{ml}$. After treatments, cells were incubated with zymosan A BioParticles Alexa Fluor 488 (Thermo, Z23373) for $2 \mathrm{~h}$ following the manufacturer's instructions. Then cells were washed with phosphate-buffered saline (PBS) to remove non-phagocytosis fluorescent particles. The samples were observed by confocal microscope (Carl Zeiss LSM710, Carl Zeiss, Oberkochen, Germany). The percentage of zymosanpositive macrophages was presented in bar charts.

Western blot analysis. To determine the levels of autophagy-related protein in Ana-1 and RAW264.7 cells, total protein contents were analyzed by western blot as described previously. ${ }^{2}$ The protein bands were incubated with specialized antibodies, and identified with HRP-conjugated secondary antibodies. Detection was performed with enhanced chemiluminescence (ECL) detection kit (Pierce, Rockford, IL, USA). Intensities in the resulting bands were quantified by ChemiDoc software (Bio-Rad, CA, USA).

Cell cycle analysis. The distribution in the cell cycle phases was determined by FACS Calibur flow cytometer (Becton-Dickinson, Fullerton, CA, USA) analysis. Ana-1 and RAW264.7 cells were treated with $300 \mathrm{IU} / \mathrm{ml} \mathrm{IFN}-\gamma$ and $200 \mathrm{ng} / \mathrm{ml} \mathrm{LPS}$, either alone or in combination with $0.1 \mathrm{IU} / \mathrm{ml}$ asparaginase for $24 \mathrm{~h}$. Then, the cells were harvested and fixed in $70 \%$ ethanol at the temperature of $-20^{\circ} \mathrm{C}$ for overnight. The cells were washed with PBS to remove fixative and stained with PI and RNaseA at $4^{\circ} \mathrm{C}$ for $30 \mathrm{~min}$. The samples were analyzed by FACS Calibur flow cytometer.

Cell proliferation analysis. The cell proliferation was determined by CFDA SE cell proliferation and tracking kit (Beyotime Institute of Biotechnology, Haimen, China). Ana-1 and RAW264.7 cells were harvested and labeled with CFSE according to the manufacturer instructions. Labeled cells were seeded in six-well plates at a density of $2 \times 10^{5}$ cells/well. Then, the cells were incubated with $300 \mathrm{IU} / \mathrm{ml} \mathrm{IFN}-\gamma$ and $200 \mathrm{ng} / \mathrm{ml}$ LPS, either alone or in combination with $0.1 \mathrm{IU} / \mathrm{ml}$ asparaginase for $24 \mathrm{~h}$. Proliferation was analyzed using FACS Calibur flow cytometer and the resulting data was analyzed by Flow Jo 10.0 program.

Transmission electron microscopy analysis. TEM assays were performed as described in our previous study. ${ }^{50}$ Ana- 1 and RAW264.7 cells were incubated with $300 \mathrm{IU} / \mathrm{ml} \mathrm{IFN}-\gamma$ and $200 \mathrm{ng} / \mathrm{ml}$ LPS, either alone or in combination with $0.1 \mathrm{IU} / \mathrm{ml}$ asparaginase for $24 \mathrm{~h}$, then harvested and fixed with ice-cold glutaraldehyde. Samples were detected with a JEM 1410 transmission electron microscope (JEOL, Inc., MA, USA) at $80 \mathrm{kV}$.

Confocal microscopy. Ana-1 and RAW264.7 cells were plated in glass bottom cell culture dishes at a density of $1 \times 10^{5} / \mathrm{ml}$. After $24 \mathrm{~h}$ of incubation, cells were treated with $300 \mathrm{IU} / \mathrm{ml} \mathrm{IFN-} \gamma$ and $200 \mathrm{ng} / \mathrm{ml} \mathrm{LPS}$, either alone or in combination with $0.1 \mathrm{IU} / \mathrm{ml}$ asparaginase for another $24 \mathrm{~h}$. Then, cells were stained with Cyto-ID Green dye and Hoechst 33342 at $37^{\circ} \mathrm{C}$ for $30 \mathrm{~min}$ following the manufacturer's instruction. All the procedures were done in the dark place and the samples were observed by an inverted confocal microscope.

Measurement of NO production. Ana-1 and RAW264.7 cells were treated with $300 \mathrm{IU} / \mathrm{ml} \mathrm{IFN}-\gamma$ and $200 \mathrm{ng} / \mathrm{ml} \mathrm{LPS}$, either alone or in combination with $0.1 \mathrm{IU} / \mathrm{ml}$ asparaginase for $24 \mathrm{~h}$. The cell supernatants were collected and assayed for NO production using Griess reagent (Beyotime Institute of Biotechnology). In brief, the samples were mixed with an equal volume of Griess reagent I and Griess reagent II. The optical density (OD) was measured at an absorbance wavelength of $540 \mathrm{~nm}$. Sodium nitrite $(0-100 \mu \mathrm{M})$ was used as a standard to assess nitrite concentrations.

ROS measurement. Reactive oxygen species assay kit (Beyotime Biotechnology, Haimen, China) was used to detect intracellular ROS generation in macrophages. Ana-1 and RAW264.7 cells were seeded into 96-well black plates and treated with $300 \mathrm{IU} / \mathrm{ml} \mathrm{IFN}-\gamma$ and $200 \mathrm{ng} / \mathrm{ml}$ LPS, either alone or in combination with $0.1 \mathrm{IU} / \mathrm{ml}$ asparaginase. After $24 \mathrm{~h}$ incubation, $10 \mu \mathrm{M}$ of the fluorescent probe DCFH-DA was added to each well, and the cells were incubated at $37^{\circ} \mathrm{C}$ for $20 \mathrm{~min}$. Subsequently, cells were washed twice with serum-free medium. A microplate reader was used to determine the OD value (excitation: $488 \mathrm{~nm}$, emission: $525 \mathrm{~nm}$ ).

Cytokine analysis. Macrophages were treated with $300 \mathrm{IU} / \mathrm{ml} \mathrm{IFN-} \gamma$ and $200 \mathrm{ng} / \mathrm{ml}$ LPS, either alone or in combination with $0.1 \mathrm{IU} / \mathrm{ml}$ asparaginase. After $24 \mathrm{~h}$ of incubation, the cell supernatants were collected and assayed for cytokine production using ELISA Kit (Boatman Biotech, Shanghai, China). The assay was performed according to the manufacturer's instructions.

MHC-II expression analysis. Ana-1 and RAW264.7 cells were treated with $300 \mathrm{IU} / \mathrm{ml} \mathrm{IFN}-\gamma$ and $200 \mathrm{ng} / \mathrm{ml} \mathrm{LPS}$, either alone or in combination with $0.1 \mathrm{IU} / \mathrm{ml}$ asparaginase for $24 \mathrm{~h}$. The cells were harvested and incubated with an antibody against FCGR2/CD32 and FCGR3/CD16 (FcR $\gamma$ blocker, BD Biosciences, San Diego, CA, USA) for $5 \mathrm{~min}$, followed by a PE-conjugated I-A/I-E antibody (BD Biosciences) for additional $30 \mathrm{~min}$ at $37^{\circ} \mathrm{C}$. Then, the cells were analyzed immediately by using a FACS Calibur flow cytometer (Becton-Dickinson).

Microscopy and photography. About $1 \times 10^{4}$ Ana-1 and RAW264.7 cells were seeded into 96-well plates. After incubation for $24 \mathrm{~h}$, cells were examined by using an inverted microscope (Nikon, Tokyo, Japan) equipped with a model digital camera.

Statistical analysis. All data were presented as mean \pm S.D.s. Statistical analysis was performed using Student's $t$-test. ${ }^{*},{ }^{* *}$, and ${ }^{* * *}$ indicated $P<0.05$, $P<0.01$, and $P<0.001$, respectively.

\section{Conflict of Interest}

The authors declare no conflict of interest.

Acknowledgements. This study was supported by National Key Basic Research Program of China (2015CB931800 and 2013CB932502), the National Natural Science Foundation of China (81573332 and 81572979), Shanghai Science and Technology Funds (14431900200), and Special Research Foundation of State Key Laboratory of Medical Genomics and Collaborative Innovation Center of Systems Biomedicine.

1. Tong WH, Pieters R, Kaspers GJ, te Loo DM, Bierings MB, van den Bos C et al. A prospective study on drug monitoring of PEG asparaginase and Erwinia asparaginase and asparaginase antibodies in pediatric acute lymphoblastic leukemia. Blood 2014; 123: 2026-2033.

2. Song $\mathrm{P}, \mathrm{Ye} \mathrm{L}$, Fan J, Li Y, Zeng $X$, Wang $Z$ et al. Asparaginase induces apoptosis and cytoprotective autophagy in chronic myeloid leukemia cells. Oncotarget 2015; 6: 3861-3873. 
3. Hays JL, Kim G, Walker A, Annunziata CM, Lee JM, Squires J et al. A phase II clinical trial of polyethylene glycol-conjugated L-asparaginase in patients with advanced ovarian cancer: early closure for safety. Mol Clin Oncol 2013; 1: 565-569.

4. Li X, Cui Y, Sun Z, Zhang L, Li L, Wang X et al. DDGP versus SMILE in newly diagnosed advanced natural killer/T cell lymphoma: a randomized controlled, multicenter, open-label study in China. Clin Cancer Res 2016; 22: 5223-5228.

5. Covini D, Tardito S, Bussolati O, Chiarelli LR, Pasquetto MV, Digilio R et al. Expanding targets for a metabolic therapy of cancer: L-asparaginase. Recent Pat Anticancer Drug Discov 2012; 7: 4-13.

6. Kafkewitz D, Bendich A. Enzyme-induced asparagine and glutamine depletion and immune system function. Am J Clin Nutr 1983; 37: 1025-1030.

7. Wang $\mathrm{H}$, Wang L, Wuxiao Z, Huang $H$, Jiang W, Li $Z$ et al. Increased serum levels of interleukin-10 predict poor prognosis in extranodal natural killer/T-cell lymphoma patients receiving asparaginase-based chemotherapy. Onco Targets Ther 2015; 8: 2589-2599.

8. Dziurzynski K, Wei J, Qiao W, Hatiboglu MA, Kong LY, Wu A et al. Glioma-associated cytomegalovirus mediates subversion of the monocyte lineage to a tumor propagating phenotype. Clin Cancer Res 2011; 17: 4642-4649.

9. Mittal SK, Roche PA. Suppression of antigen presentation by IL-10. Curr Opin Immunol 2015; 34: 22-27.

10. Ruffell B, Chang-Strachan D, Chan V, Rosenbusch A, Ho CM, Pryer N et al. Macrophage IL-10 blocks CD8+ T cell-dependent responses to chemotherapy by suppressing IL-12 expression in intratumoral dendritic cells. Cancer Cell 2014; 26: 623-637.

11. Kullas AL, McClelland M, Yang HJ, Tam JW, Torres A, Porwollik S et al. L-asparaginase II produced by Salmonella typhimurium inhibits $\mathrm{T}$ cell responses and mediates virulence. Cell Host Microbe 2012; 12: 791-798.

12. Torres A, Luke JD, Kullas AL, Kapilashrami K, Botbol Y, Koller A et al. Asparagine deprivation mediated by Salmonella asparaginase causes suppression of activation-induced $T$ cell metabolic reprogramming. J Leukoc Biol 2016; 99: 387-398.

13. Rostam HM, Singh S, Salazar F, Magennis P, Hook A, Singh T et al. The impact of surface chemistry modification on macrophage polarisation. Immunobiology 2016; 221: 1237-1246.

14. Epelman S, Lavine KJ, Randolph GJ. Origin and functions of tissue macrophages. Immunity 2014; $41: 21-35$.

15. Murray PJ, Allen JE, Biswas SK, Fisher EA, Gilroy DW, Goerdt S et al. Macrophage activation and polarization: nomenclature and experimental guidelines. Immunity 2014; 41: $14-20$.

16. Sica A, Mantovani A. Macrophage plasticity and polarization: in vivo veritas. J Clin Invest 2012; 122: 787-795.

17. Warnatsch A, loannou M, Wang Q, Papayannopoulos V. Inflammation. Neutrophil extracellular traps license macrophages for cytokine production in atherosclerosis. Science 2015; 349: 316-320.

18. Rossol M, Heine H, Meusch U, Quandt D, Klein C, Sweet MJ et al. LPS-induced cytokine production in human monocytes and macrophages. Crit Rev Immunol 2011; 31: 379-446.

19. Tripathi AK, Rathi N, Suke SG, Banerjee BD, Ahmed RS, Mahajan P et al. Alteration of superoxide- and nitric oxide-mediated antimicrobial function of macrophages by in vivo cocaine exposure. Can J Physiol Pharmacol 2008; 86: 64-69.

20. Wynn TA, Vannella KM. Macrophages in tissue repair, regeneration, and fibrosis. Immunity 2016; 44: 450-462.

21. Klionsky DJ, Abdelmohsen K, Abe A, Abedin MJ, Abeliovich H, Acevedo Arozena A et al. Guidelines for the use and interpretation of assays for monitoring autophagy (3rd edition). Autophagy 2016; 12: 1-222.

22. Klionsky DJ, Abdalla FC, Abeliovich H, Abraham RT, Acevedo-Arozena A, Adeli K et al. Guidelines for the use and interpretation of assays for monitoring autophagy. Autophagy 2012; 8: 445-544.

23. Klionsky DJ, Abeliovich H, Agostinis P, Agrawal DK, Aliev G, Askew DS et al. Guidelines for the use and interpretation of assays for monitoring autophagy in higher eukaryotes. Autophagy 2008; 4: 151-175.

24. Ireland JM, Unanue ER. Autophagy in antigen-presenting cells results in presentation of citrullinated peptides to CD4 T cells. J Exp Med 2011; 208: 2625-2632.

25. Shibutani ST, Saitoh T, Nowag H, Munz C, Yoshimori T. Autophagy and autophagy-related proteins in the immune system. Nat Immunol 2015; 16: 1014-1024.

26. Zhong Z, Umemura A, Sanchez-Lopez E, Liang S, Shalapour S, Wong J et al. NF-kappaB restricts inflammasome activation via elimination of damaged mitochondria. Cell 2016; 164 : 896-910.

27. Zeng TS, Liu FM, Zhou J, Pan SX, Xia WF, Chen LL. Depletion of Kupffer cells attenuates systemic insulin resistance, inflammation and improves liver autophagy in high-fat diet fed mice. Endocr J 2015; 62: 615-626.

28. Kang YH, Cho MH, Kim JY, Kwon MS, Peak JJ, Kang SW et al. Impaired macrophage autophagy induces systemic insulin resistance in obesity. Oncotarget 2016; 7: 35577-35591.
29. Choi SH, Gonen A, Diehl CJ, Kim J, Almazan F, Witztum JL et al. SYK regulates macrophage MHC-II expression via activation of autophagy in response to oxidized LDL. Autophagy 2015; 11: 785-795.

30. Shao BZ, Han BZ, Zeng YX, Su DF, Liu C. The roles of macrophage autophagy in atherosclerosis. Acta Pharmacol Sin 2016; 37: 150-156.

31. Prieto P, Rosales-Mendoza CE, Terron V, Toledano V, Cuadrado A, Lopez-Collazo E et al. Activation of autophagy in macrophages by pro-resolving lipid mediators. Autophagy 2015; 11: 1729-1744.

32. Salpeter SJ, Pozniak Y, Merquiol E, Ben-Nun Y, Geiger T, Blum G. A novel cysteine cathepsin inhibitor yields macrophage cell death and mammary tumor regression. Oncogene 2015; 34: 6066-6078.

33. Cassado Ados A, D'Imperio Lima MR, Bortoluci KR. Revisiting mouse peritoneal macrophages: heterogeneity, development, and function. Front Immunol 2015; 6: 225

34. Drozina G, Kohoutek J, Jabrane-Ferrat N, Peterlin BM. Expression of MHC II genes. Curr Top Microbiol Immunol 2005; 290: 147-170.

35. Lodder J, Denaes T, Chobert MN, Wan J, El-Benna J, Pawlotsky JM et al. Macrophage autophagy protects against liver fibrosis in mice. Autophagy 2015; 11: 1280-1292.

36. Lavandero S, Chiong M, Rothermel BA, Hill JA. Autophagy in cardiovascular biology. J Clin Invest 2015; 125: 55-64.

37. Laplante M, Sabatini DM. mTOR signaling in growth control and disease. Cell 2012; 149 : 274-293

38. Lorin S, Hamai A, Mehrpour M, Codogno P. Autophagy regulation and its role in cancer. Semin Cancer Biol 2013; 23: 361-379.

39. Pieters R, Hunger SP, Boos J, Rizzari C, Silverman L, Baruchel A et al. L-asparaginase treatment in acute lymphoblastic leukemia: a focus on Erwinia asparaginase. Cancer 2011; 117: 238-249.

40. Newsholme P. Why is L-glutamine metabolism important to cells of the immune system in health, postinjury, surgery or infection? J Nutr 2001; 131: 2515S-2522S, discussion 2523S-2514S.

41. Ayala-Nunez NV, Hoornweg TE, van de Pol DP, Sjollema KA, Flipse J, van der Schaar HM et al. How antibodies alter the cell entry pathway of dengue virus particles in macrophages. Sci Rep 2016; 6: 28768

42. Spellberg B, Edwards J Jr, Ibrahim A. Novel perspectives on mucormycosis: pathophysiology, presentation, and management. Clin Microbiol Rev 2005; 18: 556-569.

43. Stavitsky AB, Xianli J. In vitro and in vivo regulation by macrophage migration inhibitory factor (MIF) of expression of MHC-II, costimulatory, adhesion, receptor, and cytokine molecules. Cell Immunol 2002; 217: 95-104.

44. Valdor R, Macian F. Autophagy and the regulation of the immune response. Pharmacol Res 2012; 66: 475-483.

45. Heras-Sandoval D, Perez-Rojas JM, Hernandez-Damian J, Pedraza-Chaverri J. The role of $\mathrm{PI}$ KK/AKT/mTOR pathway in the modulation of autophagy and the clearance of protein aggregates in neurodegeneration. Cell Signal 2014; 26: 2694-2701.

46. Wang S, Li Y, Fan J, Wang Z, Zeng X, Sun Y et al. The role of autophagy in the neurotoxicity of cationic PAMAM dendrimers. Biomaterials 2014; 35: 7588-7597.

47. Martinez-Lopez N, Singh R. ATGs: Scaffolds for MAPK/ERK signaling. Autophagy 2014; 10 : 535-537.

48. Sergin I, Razani B. Self-eating in the plaque: what macrophage autophagy reveals about atherosclerosis. Trends Endocrinol Metab 2014; 25: 225-234.

49. Ponpuak M, Deretic V. Autophagy and p62/sequestosome 1 generate neo-antimicrobial peptides (cryptides) from cytosolic proteins. Autophagy 2011; 7: 336-337.

50. Li Y, Zhu H, Zeng X, Fan J, Qian X, Wang S et al. Suppression of autophagy enhanced growth inhibition and apoptosis of interferon-beta in human glioma cells. Mol Neurobiol 2013 47: $1000-1010$.

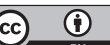

Cell Death and Disease is an open-access journal published by Nature Publishing Group. This work is licensed under a Creative Commons Attribution 4.0 International License. The images or other third party material in this article are included in the article's Creative Commons license, unless indicated otherwise in the credit line; if the material is not included under the Creative Commons license, users will need to obtain permission from the license holder to reproduce the material. To view a copy of this license, visit http://creativecommons.org/licenses/by/4.0/

(C) The Author(s) 2017 